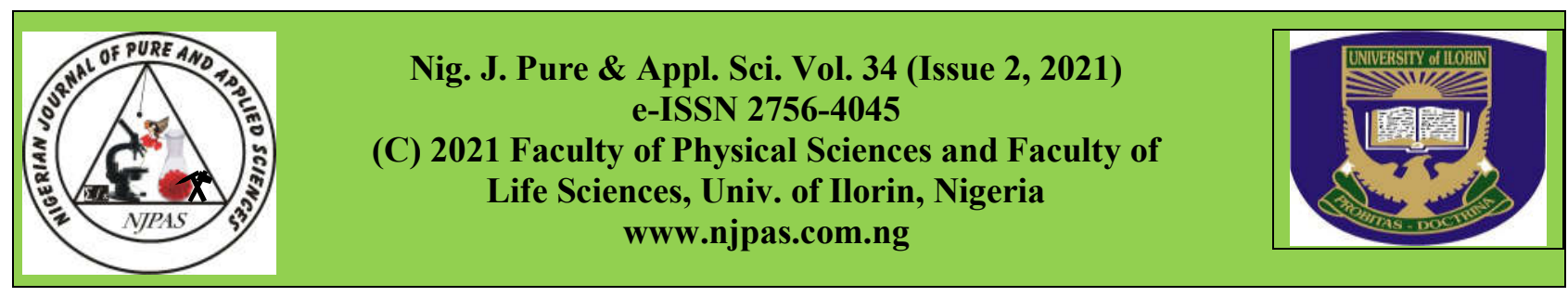

\title{
Experimental Investigation on the effect of Chemical Pretreatments of Slow-Pyrolyzed Nigerian Jatropha curcas L. Biomass Residues on Pyrolytic oil
}

\author{
Fatai Abiola Lateef ${ }^{1,2^{*}}$ and Helen Olayinka Ogunsuyi ${ }^{2}$
}

Page | $4126{ }^{1}$ Department of Science Laboratory Technology, Chemistry Unit, Federal Polytechnic, P.M.B. 1037, Idah, Kogi State, Nigeria

${ }^{2}$ Department of Chemistry, The Federal University of Technology, P.M.B. 704, Akure, Ondo State, Nigeria

Date Received: 22-07-2021

Date Accepted: 02-10-2021

DOI: https://doi.org/10.48198/NJPAS/21.B07

\section{ABSTRACT}

In Nigeria, assemblage and discarding of residues from energy crops are increasingly becoming laborious and costly and may pose serious environmental challenges if not correctly managed. The Energy Commission of Nigeria's long term (2016-2030) plan on the nation's energy requirements is entirely non-fossil. This is attributable to the global decline of fossil fuel sources, soaring prices, climate crisis and the need to utilize hitherto abundant biomass resources for energy and chemical feedstocks purposes in Nigeria. In this research, an experimental study on the bio-oil generated through slow pyrolysis of Jatropha curcas L. biomass residues - Jatropha curcas L. seed shell (JSS) and Jatropha curcas L. fruit hull (JFH) were realized in a fixed bed reactor at $450{ }^{\circ} \mathrm{C}$ in a batch-wise step, biomass sample $(1.14 \mathrm{~mm})$ particle size, designed by authors. The biomass samples were subjected to pretreatment with $4 \%$ sulphuric and sodium hydroxide solutions each respectively. The Chemical compositions and functional groups available in the bio-oil of both raw and pretreated biomasses obtained at $450{ }^{\circ} \mathrm{C}$ were investigated by Gas Chromatography-Mass Spectrometry (GCMS) and Fourier Transform- Infrared (FT-IR) spectroscopy analysis respectively. Scanning Electron Microscopy (SEM) was used to look into the residual biomass surface morphology of pretreated and untreated Jatropha curcas L. waste of JSS and JFH. The results acquired disclosed that the bio-oil obtained from JSS and JFH might be a principal liquid fuel starting point and chemical feedstocks.

Keywords: Energy crops; Biomass resources; Slow pyrolysis; Chemical compositions; Functional groups; Bio-oil.

\section{Introduction}

The flourishing global biodiesel market has captivated investors and project developers in various countries of the world to contemplate biofuels production from self-sustaining nonedible biomass feedstocks. This is an attempt to lessen greenhouse gas emissions (which are released during the combustion of fossil fuels) which contribute to global warming from fossil resources and reduce food versus energy issues. Furthermore, there are soaring energy requests all over the globe and consensus from researchers that fossil energy sources are limited. This makes it

\section{Corresponding Author: Fatai Abiola Lateef.}

Department of Science Laboratory Technology, Chemistry Unit, Federal Polytechnic, P.M.B. 1037, Idah,

Kogi State, Nigeria.

Email: latfatab@gmail.com

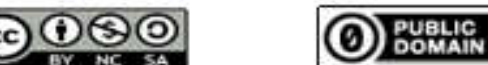


increasingly necessary to promote a renewable energy source of unlimited duration, little environmental impacts and which are technically achievable and widely available (Lateef et al., 2014a; Lateef and Ogunsuyi, 2021). Biofuels

Page | 4127 synthesis from biomass is of interest because these biomasses are renewable, biodegradable, easily accessible and environment-friendly resources (Lateef et al., 2018, Lateef and Asadu, 2018). Jatropha curcas L. is among the list of novel bioenergy crops in the regional potential appraisal carried out by Linde, 2012 in biofuel categories currently considered in fifteen ECOWAS countries (including Nigeria). Jatropha curcas L. (Jatropha) is a prominent multipurpose plant with many characteristics and appreciable potentials and are in abundance in Nigeria. The plant belongs to the family - Euphorbiaceae, which emanated in Central America, but is widespread in West and Central Africa countries (Abdul Khalid et al., 2012; Lateef et al., 2014b; Lateef et al., 2014c; Lateef et al., 2021). In Nigeria, the present focus of this prominent plant is largely on biodiesel (Lateef, 2010), the plant produces many other indisputably useful products (Openshaw, 2000; Manurung et al., 2009; Parawira, 2010; Islam et al., 2011; Abdul Khalil, 2013), but research efforts on valorisation is still at infancy in Nigeria. Currently, there is a wide abundance of Jatropha plants in Nigerian states of Kebbi, Kogi, Sokoto, Zamfara, Katsina, Kano, Jigawa, Bauchi, Yobe, Borno, Adamawa and Gombe (Galadima et al., 2011). The oil derived from this plant find their uses in the production of soaps/detergents, cosmetics, biodiesels, insecticides, alkyd resins, transformer oil, biolubricants e.t. c.; nevertheless, the leftover from this plant- fruit hulls, husks or shells and de-oiled seed kernels are disposed of as waste.

There are many thermochemical procedures for the transformation of biomass into bioenergy or biofuels. The technique consists of gasification, pyrolysis, direct combustion/carbonization, transesterification, hydrocracking and biochemical conversion technologies. Among the thermochemical conversion processes, pyrolysis is acknowledged as a favourable technology for biooil production (Ertas and Alma, 2010) and is considered as the technique by which fuels and chemicals can be produced from biomass materials (Capunitan and Capareda, 2013). Biomass pyrolysis is one of the known pathways for biomass conversion into bio-oil, which can partially replace fossil fuels, can lead to high added-value products and concurrently contribute to beneficiation of vast amounts of assembled waste biomass feedstock (Iliopoulou et al., 2018). Pyrolysis is one of the identified simple conversion techniques to produce bioenergy from lignocellulosic biomass, energy crops and other biomass residues. Pyrolysis means thermal decomposition or cracking of biomass under a reduced oxygen environment or in an oxygen-free environment. Cellulose swiftly decomposes to gaseous products and residual char when biomass is treated at temperatures greater than $300{ }^{\circ} \mathrm{C}$, because at lower temperatures, the decomposition is much slower and the products launched are less volatile (Kumar et al., 2009).

There are three major pyrolysis paths for the conversion of biomass feedstocks to a wide variation of fuels and chemicals (Balat et al., 2009). These are conventional pyrolysis, fast pyrolysis and flash pyrolysis. Conventional pyrolysis is described as pyrolysis, which occurs under a slow heating rate and is occasionally called slow pyrolysis. Compared to fast pyrolysis, the slow pyrolysis oil recovery is lower in mass yields but with lower oxygen and water content and better thermal stability (Elliot, 2007). Generally, Pyrolysis of biomass at hightemperature yields Charcoal (Carbon and ash called biochar), Condensable vapour (bio-oil / biocrude, pyrolysis oil, pyrolytic oil), noncondensable gasses $\left(\mathrm{CO}, \mathrm{CO}_{2}\right.$, Hydrogen) light molecular weight hydrocarbon gasses $\left(-\mathrm{CH}_{4}\right.$, syngas and producer gas). Bio-oil is the liquid condensate arising from vapours of a pyrolysis 
reaction. Bio-oil is a dark brownish viscous liquid that bears some appearance to fossil crude oil (Sadaka and Boateng, 2009), and is viewed as a complex oxygenated compound comprising of water, water-soluble compounds, such as acids, Page | 4128 esters e.t.c and water-insoluble compounds (usually called pyrolytic lignin). Generally, pyrolysis of biomass gives a complex mixture of products, its chromatographic analyses demand coupling of these instruments with a mass selective detector to assist the recognition of eluted products (Shah et al., 2016b). These eluted products (condensate i.e Bio-oil) could be utilised as fuel when upgraded. It could also be harnessed for Wood preservation, Pesticides, Adhesives, Asphalt-paving substitution, Bio-carbon electrodes, Coal dust suppression, fertilizers, Antioxidants, Food additives, Impermiabilizer, Road de-icer and Surfactants (Murray et al., 2014). For a better understanding of Bio-oil functional group compositional analysis, Fourier transforms infrared spectroscopy (FT-IR) is usually used.

Conversion of Jatropha plant parts into liquid biofuels such as Bio-oil involves three major unit operations: pretreatment, hydrolysis, pyrolysis. Pretreatment is necessary to boost the digestibility of lignocellulosic material (Hendriks and Zeeman, 2009). Pretreatment is necessary to depolymerize the complex lignin and cellulose structure and segregate lignin from cellulose and hemicellulose through hydrolysis (Den et al., 2018). Pretreatment can also alter cellulose crystallinity, to magnify its depolymerization rate (Chundawat et al., 2011). Hydrolysis requires impregnating the biomass in alkaline solutions and mixing it at a target temperature for a definite amount of time (Menon and Rao, 2012).

Biomass pretreatment can be categorized into four major classifications: physical, physicochemical, chemical and biological (Menon and Rao, 2012). Physical pretreatment involves mechanical processing for size reduction such as milling, chopping, pulverizing, irradiation (using gamma rays, microwave etc) and extrusion to strengthen hydrolysis or biodegradability of lignocellulosic materials, which in turn lower the cellulose crystallinity. Physico-chemical pretreatments include steam explosion, ammonia fibre explosion (AFEX) / ammonia recycle percolation, Microwave-chemical pretreatment, liquid-hot water pretreatment. Chemical pretreatment consists of acid pretreatment, alkaline pretreatment, green solvents (ionic liquids). Biological pretreatment utilises wood degrading microorganisms, including white-, brown-, soft-rot fungi and bacteria to modify the chemical composition and/or structure of the lignocellulosic biomass. So far, there is no commercially realizable solution to effective pretreatment of Jatropha curcas L. biomass for the making of biobased products. Many pretreatment methods have been canvassed in the literature. Among these methods, mild alkaline and dilute acid pretreatments are more realistically useful due to fewer drawbacks when juxtaposed with others (Deng et al., 2008). Keeping in view the significance of mild alkaline and dilute acid pretreatments, this study aims at the pretreatment of JSS and JFH with $4 \% \mathrm{NaOH}$ and $\mathrm{H}_{2} \mathrm{SO}_{4}$. Generally, as biomass is being pretreated, all the surface characteristics of the residual biomass change progressively.

Previous reports on pyrolysis of biomass wastes to bio-oil, biochar through flash / fast and slow pyrolysis have proved successful (Lee et al., 2017; Ogunjobi and Lajide, 2013); to the best of our knowledge and the past work consulted so far, little or no work has been reported on the effect of pretreatments on chemical compositions, type of chemical groups present and residual biomass surface morphology of Nigerian JSS and JFH. Therefore, this work aimed to produce bio-oils from JSS and JFH using $4 \%$ acid and alkaline hydrolysis, characterize the bio-oils for chemical compositions using GC-MS, verify the applicability of infrared spectroscopy (FT-IR) to gain fundamental knowledge of the type of 
chemical group present and study the residual biomass surface morphology using Scanning electron microscopy (SEM).

\section{Materials and Methods \\ Page | 4129 Biomass sample and sample preparation}

The biomass samples used for this study were Jatropha curcas L. seed shell and fruit hull. The method used is as contained in our previous publications (Lateef et al., 2021; Lateef and Ogunsuyi, 2021). Semi-dried Jatropha curcas L. fruits matured to a dark-brown state were picked manually in December 2017 from many Jatropha plantations located in Idah $\left(7^{\circ} 05^{\prime} 00^{\prime \prime} \mathrm{N} 6^{\circ} 45^{\prime} 00^{\prime}\right.$ 'E $/ 7.08333^{\circ} \mathrm{N} \quad 6.75000^{\circ} \mathrm{E}$ ), Kogi State, Nigeria. The Jatropha fruits were sorted separately to remove extraneous materials. The hulls of the fruits were separated from the seeds and were dried under the sun for 30 days. The dried hull was milled with a Grinding machine (SFE 200, 6.5 HP, Japan) and the pulverized sample were sieved through a laboratory test sieve (Standard test sieve, SETHI BSS 14, As per IS: $460=1.41 \mathrm{~mm}$ ) to $\leq 2 \mathrm{~mm}$ particle size. Jatropha husk (seed shell) were deshelled manually by separating the kernels from the seeds. The seed shell was sun-dried for more than 30 days and milled in a Grinding machine (SFE 200, 6.5 HP, Japan) and then sieved (Standard test sieve, SETHI BSS 14, As per IS: $460=1.14 \mathrm{~mm})$ to $\leq 2 \mathrm{~mm}$ particle size. The leftover Kernels were milled in a Grinding machine (SFE 200, 6.5 HP, Japan).

The milled Jatropha fruit hull and seed shell were stored in perforated bags at room temperature (within a range of $26-32{ }^{\circ} \mathrm{C}$ ) until used. All reagents used are of analytical grade and were used as received.

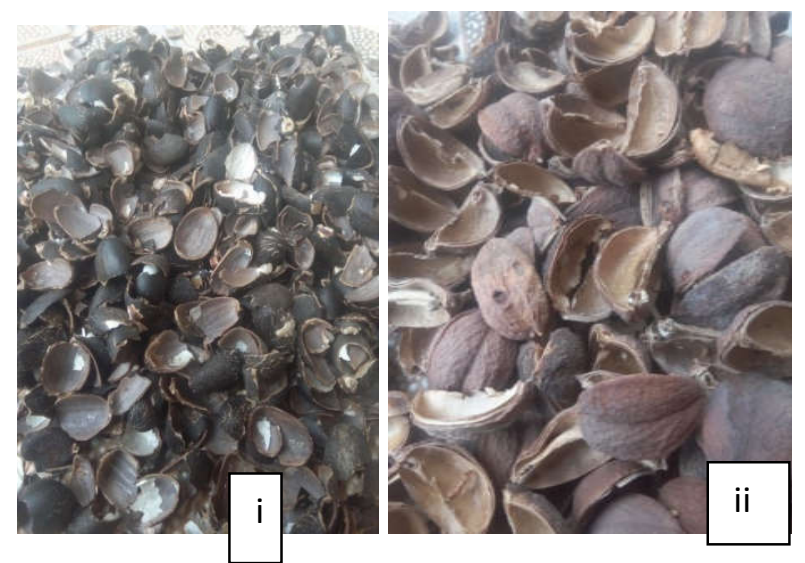

Fig 1: (i) Jatropha curcas L. seed shell (JSS) and (ii) Jatropha curcas L. fruit hull (JFH) biomasses

\section{Proximate analysis of the raw feedstock and Higher Heating value}

The initial moisture content of the samples was determined by the method of oven drying (Subroto et al., 2015) modified, while that of Percentage ash was carried out based on AOAC, 1996 as follows:

Clean porcelain dishes were dried in an oven for about $30 \mathrm{~min}$. at $105{ }^{\circ} \mathrm{C}$, cooled at room temperature in a desiccator and weighed $\left(\mathrm{w}_{1}\right)$. About $1.000 \mathrm{~g}\left(\mathrm{w}_{2}\right)$ of the pulverized samples were then placed in the muffle furnace at $500{ }^{\circ} \mathrm{C}$ for 3 hours. The crucible containing the samples were allowed to cool in a desiccator and then weighed $\left(\mathrm{w}_{3}\right)$.

Percentage ash and fixed carbon of the biomass were estimated from equations 1 - 2

$$
\% \text { ash }=\frac{w_{3}-w_{2}}{w_{2}} \times 100
$$

Percentage Volatile matter was determined based on Ibitoye, 2017 and that of Percentage Fixed carbon was computed by subtracting the total of moisture, volatile matter and ash percentage from 100:

$\%$ fixed carbon $=100-(\%$ moisture $+\%$ volatile matter $+\%$ ash) 
The determination of Higher Heating/Calorific values was done using an e2k calorimeter (model: Cr1001).

A mass sample of $0.5 \mathrm{~g}$ was weighed on the $2 \mathrm{~cm}$ Page | 4130 firing cotton tied to the firing wire on the lid assembly and placed inside the metal crucible. The lid assembly was then placed inside the bomb (vessel) air-tight. The bomb was filled in with oxygen at $3000 \mathrm{MPa}$. The equipment was connected to a power source and the F1 on the keyboard attached to the e $2 \mathrm{k}$ Calorimeter and the sample weighed $(0.5 \mathrm{~g})$ were entered. The bomb Calorimeter was fired after placing the bomb inside it and the result was displayed on the screen after the combustion process. The bomb was removed and degas properly. The equipment was shut and the oxygen cylinder closed.

Wet chemical analyses (Compositional/ Fibre analysis which comprises Klason lignin, Hemicellulose and Cellulose) of Jatropha curcas L. waste biomasses were carried out according to the wood industry sector methods and as described in Carrier et al., 2011 (modified) and the results published elsewhere

\section{Pretreatment of J.curcas biomass feedstocks}

J. curcas L. biomass feedstocks (JSS, JFH) pretreatment were carried out in a pilot-scale reactor designed by the authors. Biomass hydrolysis runs were carried out in a modified pressure pot with a continuous temperature control probe, where the temperature inside the vessel is maintained homogeneous. The treatment was performed on JSS, JFH at $120{ }^{\circ} \mathrm{C}, 30 \mathrm{~min}$. residence time, with a different solid to liquid ratio.

\section{Acid hydrolysis}

In the pretreatment with dilute acid, biomass samples were soaked separately in $4 \%$ sulphuric acid solution (Biomass liquid ratio was calculated in 1: 9; $500 \mathrm{~g}$ of biomass $=4500 \mathrm{~mL}$ of water) and subjected to heating at $109{ }^{\circ} \mathrm{C}$ for $30 \mathrm{~min}$ (Tutt et al., 2012) modified. The pretreated biomass was washed thoroughly with tap water, then $0.1 \mathrm{M}$ sodium hydroxide was added to neutralize the acid, stirred thoroughly with tap water until neutral $(\mathrm{pH}$ adjusted to 7.0). The sieve was used to drain the supernatant from the residual biomass. The residual biomass was air-dried for 14 days and weighed. Air-dried residual biomass collected were subjected to further analysis and used for biofuel synthesis.

\section{Alkaline hydrolysis}

The alkaline pretreatment was carried out using 4 wt. \% sodium hydroxide solution (Guilherme et al., 2017) modified. The biomass feedstocks (JSS and JFH) were immersed in a 4 wt. \% sodium hydroxide solution (Biomass liquid ratio was calculated in 1: 9; $500 \mathrm{~g}$ of biomass $=4500 \mathrm{~mL}$ of water) and subjected to heating at $109^{\circ} \mathrm{C}$ (followed by intermittent shaking) for $30 \mathrm{~min}$. The pretreated biomass was washed thoroughly, then $0.005 \mathrm{M}$ of $\mathrm{H}_{2} \mathrm{SO}_{4}$ was introduced to neutralize the base, stirred thoroughly with tap water until neutral $(\mathrm{pH}$ adjusted to 7.0). The sieve was used to drain the supernatant from the residual biomass. The residual biomass was air-dried for 14 days and weighed. Air-dried residual biomass collected were subjected to further analysis and used for biofuel synthesis.

\section{Slow Pyrolysis of biomass feedstock}

Pyrolysis reactor is of fixed bed type and made of Brass steel and cylindrical shape. The cylindrical reactor is having an internal diameter of $20 \mathrm{~mm}$ and height of $70 \mathrm{~mm}$, which is placed in an electric furnace with a heating element of $1 \mathrm{~mm}$ thickness. The electrical furnace is connected to the Electrotechnical system: temperature controller unit (Temperature controller, C900FK07-M*EN, 0-1300 ${ }^{\circ} \mathrm{C}, 220 \mathrm{~V}$, AC 50/60Hz, Japan), Contactor (Cutler-Hammer, C316KNA3, Germany and a Sensor (Thermocouple, K -Type, China) which governs the inside temperature of the furnace and another temperature controller unit which governs the inside temperature of the reactor. To create an 
oxygen-free environment, the reactor was neatly packed with a heat-resistant gasket. The temperature of the furnace was set at $450{ }^{\circ} \mathrm{C}$ and as the biomass sample ( $\leq 2 \mathrm{~mm}$ particle size, $1000 \mathrm{~g}$ ) gets pyrolysed at about $245^{\circ} \mathrm{C}$, volatiles released,

Page | 4131 exits from the volatile delivery tube and are passed through the Liebig condenser. The sample was pyrolysed to the set pyrolysis temperature of 450 ${ }^{\circ} \mathrm{C}$ and held for about 45-50 min. until no release gas was observed from the reactor. The pyrolysis liquid products - viscous phase (Bio-oil) and aqueous phase (water) were collected via flat bottom flask by condensing in the condenser and cold traps maintained at about $0-5{ }^{\circ} \mathrm{C}$. The viscous phase was separated from the aqueous phase using a colloquially sep funnel, weighed and stored in a plastic container for further use and analysis. The biochar resulting from pyrolysis was equally weighed and stored inside a polythene bag.

\section{Analytical methods}

Bio-oil and pretreated residual biomass obtained were further analysed using the following analytical methods to obtain information on pyrolysis product / residual biomass characteristics.

\section{Gas Chromatography-Mass Spectrometry (GC- MS) of the Bio-oil.}

\section{Extraction and cleaning up of the extracts}

Five (5) $\mathrm{mL}$ of the sample was weighed into a beaker and $10 \mathrm{~mL}$ of hexane was added. The sample was sonicated for $10 \mathrm{~min}$ in an ultrasonic bath and the extract was transferred to another beaker. The extraction was repeated with $10 \mathrm{~mL}$ of the solvent mixture. The extracts were combined, concentrated to about $2.0 \mathrm{~mL}$. Clean-up of the extract was done with a glass syringe loaded with silica gel, glass wool and anhydrous sodium sulphate and then eluted with $5 \mathrm{~mL}$ of hexane. The purified extracts were then reconstituted in $2 \mathrm{~mL}$ hexane.

The GC-MS was used to identify the chemical compositions of the bio-oil. The analysis was executed using Agilent Technologies 7890 A equipped with 5975 MSD with HP-5ms capillary column (30 m length, $0.32 \mathrm{~mm}$ internal diameter, $0.25 \mu \mathrm{m}$ thickness). Helium gas is used as carrier gas at a constant flow rate of $1 \mathrm{~mL}$ per min. The injection was achieved in spitless mode and the injector temperature was set at $250{ }^{\circ} \mathrm{C}$. The oven temperature was programmed from $90{ }^{\circ} \mathrm{C}$ for 0 $\mathrm{min}$, then at $3{ }^{\circ} \mathrm{C}$ per min to $180{ }^{\circ} \mathrm{C}$ for $10 \mathrm{~min}$. Identification of the compounds was carried out by comparing the spectra data of the sample with reference spectra in spectra libraries (NIST).

\section{Fourier Transform- Infrared (FT-IR) analysis of the Bio-oil}

The surface chemical properties of the raw and hydrolysed (acid and alkali) Bio-oil achieved through slow pyrolysis at $450{ }^{\circ} \mathrm{C}$ were performed using an Alpha sample compartment RT-Dia TGS with serial number 104319 . About $0.4 \mathrm{~mL}$ of the Bio-oil sample were smeared to cover the sample crystal. The absorption bands were obtained at 4 $\mathrm{cm}^{-1}$ with a $400-4000 \mathrm{~cm}^{-1}$ scan range. Spectra were collected in $40 \mathrm{sec}$. The data were compiled using OMNIC ${ }^{\mathrm{TM}}$ spectroscopy software displaying spectrum region, absolute threshold and sensitivity.

\section{Scanning Electron Microscopy (SEM) analysis of raw and hydrolyzed samples}

The morphological characteristics of raw (unmodified) and hydrolysed (modified) Jatropha curcas L. biomass used for Bio-oil production were studied by electron microscope (SEM, JSM6390LV，6733B-IUUS-SN, Thermo Electron Corporation, USA) adapted with an energy dispersive X-ray (EDX) Spectrometer and X-max detector (Oxford-instruments, INCA 400, UK). The samples were placed on the SEM stub using double-sided carbon tape, fitted into the chamber controlled at around $1.4 \times 10^{-3}, 15 \mathrm{kV}$ accelerating voltage, $5-100 \mu \mathrm{m}$ working distances and 505,000 times magnification. 


\section{Results}

\section{Proximate Analyses}

Proximate analysis of fuel or biomass gives the percentage of the materials that burn in a gaseous

Page | 4132 state (volatile matter), in the solid-state (fixed carbon), and the percentage of inorganic waste material (ash) and hence is of major significance for biomass energy use. Table 1 shows the results of JSS and JFH biomass proximate analyses. The physicochemical properties of the bio-oil are published elsewhere.

\section{Characterization of the tested Biomass}

The results obtained for the Proximate and Calorific (Heating) value of the tested biomass are shown in Table 1.

Table 1: Characterization of the tested (raw, untreated/ untorrefied) Jatropha waste Biomass

\begin{tabular}{|c|c|c|}
\hline \multirow[t]{2}{*}{ Analysis } & \multicolumn{2}{|l|}{ Waste Biomass } \\
\hline & JSS & $\mathrm{JFH}$ \\
\hline \multicolumn{3}{|l|}{ Proximate analysis } \\
\hline Moisture content & 8.79 & 10.14 \\
\hline Ash content & 4.99 & 16.50 \\
\hline Volatile matter (VM) & 71.80 & 54.73 \\
\hline Fixed carbon (FC) & 14.42 & 18.63 \\
\hline \multicolumn{3}{|l|}{ Calorific (heating) } \\
\hline value $(\mathrm{MJ} / \mathrm{Kg})$ & 17.37 & 13.80 \\
\hline
\end{tabular}

\section{Moisture content}

The moisture content is a critical efficiency parameter because it hurts combustion processes thereby affects the calorific value of biomass material; it also interferes with transportation costs, storage and drying of the biomass (Rambo et al., 2015).

The moisture content of JSS and JFH was relatively higher $-8.79 \%$ and $10.14 \%$ respectively, but are within the range accepted for biomass conversion to fuel use. Singh et al., 2008 reported $10.75 \%, 12.35 \%$ for JSS and JFH respectively. According to Grover and Mishra (1996), Moisture content should be as low as possible, normally in the range of 10-15 percent for any potential agro-residues to be reasoned for thermochemical conversion. Generally, when the moisture content is low, the pellets or briquettes produced from the biomass will effortlessly be ignited and that no slagness during burning will occur (Akintaro et al., 2017).

\section{Ash Content}

The ash content of biomass varies significantly. The ash content is a non-combustible constituent or matter after the ignition of biomass at a high temperature. From Table 1, the ash content of $J$. curcas L. waste was $4.99 \%$ for JSS and $16.50 \%$ for JFH respectively. The JSS ash content of 4.99 $\%$ is within the ash content of other agro residues: $4.2 \%, 4.3 \%, 4.6 \%, 4.8 \%$ for Tamarind husk, Coffee husk, Cotton shells, tannin waste and Almond shell respectively (Grover and Mishra, 1996). The ash content of $4.99 \%$ for JSS in the present study was higher than values reported in some other studies, e.g. $4.00 \%$ (Nahar and Ozores-Humpton, 2011). The JFH has an ash content of $16.50 \%$. The JFH biomass ash content is lower than $22.4 \%$ for rice husk, $19.1 \%$ for tobacco dust and $28.2 \%$ for de-oiled bran (Grover and Mishra, 1996). The JFH ash content is higher than $14.88 \%$ (Nahar and Ozores-Humpton, 2011). A high concentration of ashes might be a threat in the furnaces since there is a higher probability of ash deposition and slags, as well as corrosion of the surfaces of the furnace. The ash content of the biomass is an indicator of slagging behaviour of the biomass, therefore lower ash content of biomass feedstock is always desirable for biomass conversion. The JFH ash composition result reveals that it has a high ash content 


\section{Volatile Matter}

Volatile matter content is another essential parameter because it gives evidence of the reactivity and ease of ignition of organic material

Page | 4133 (Flores et al., 2017.) The volatile matter for JSS and $\mathrm{JFH}$ is $71.80 \%$ and $54.73 \%$ respectively. Volatile matter is described as a solid material in fuel that when heated at a specific temperature, converts directly into a gaseous phase without undergoing a liquid phase (Acar and Ayanoglu, 2012). This means there is more solid content that is reactive and could easily ignite when heated in JSS than JFH. Other raw biomass with the high volatile matter according to Chen et al., 2015 are bagasse $(80.7 \%$ ), Leucaena (86.1\%), Microalgae (70.1\%), Oil palm fibre $(72.5 \%)$, grass $(82.4 \%)$, rice husk $(79.5 \%)$, sawdust $(84.5 \%)$, spruce $(85.2$ $\%$ ) which can be employed for thermochemical conversion.

\section{Fixed Carbon}

Fixed carbon is the solid combustible residue that remains after biomass is heated and the volatile matter is expelled. This is determined by subtracting the percentages of moisture, volatile matter and ash from the biomass sample. The fixed carbon calculated for JSS and JFH is 14.42 $\%$ and $18.63 \%$ respectively. There are variations in values of fixed carbon reported in various studies for JSS and JFH. The fixed carbon reported by various studies from other countries are as follows: $24.99 \%$ (Singh et al., 2008) India, $11.27 \%$ (Sricharoenchaikul and Atong, 2009) Thailand. The same observation was observed in the values of fixed carbon reported for JFH: 16.38 $\%$ (Singh et al., 2008) India.

\section{Higher Heating (Calorific) value (HHV)}

The Higher heating values obtained are 17.37 and $13.80 \mathrm{MJ} / \mathrm{Kg}$ for JSS and JFH respectively. The Higher heating value is the amount of heat energy, which is emitted by biomass at the time of combustion under set conditions of the experiment and it specifies the total energy potential obtainable in the biomass (Odetoye et $a l ., 2018)$. The HHV of Nigerian JSS is higher than 16.93 MJ/Kg (Singh et al., 2008) and 16.50 $\mathrm{MJ} / \mathrm{Kg}$ (Kratzeisen and Muller, 2009) and thus similar to wood which is the main source of energy in developing countries until now. The reported JFH HHV of $15.75 \mathrm{MJ} / \mathrm{Kg}$ by Singh et al., 2008 as compared to $13.80 \mathrm{MJ} / \mathrm{Kg}$ in this study may be due to the method employed in drying the biomass sample. The longer the drying time, the lower the moisture content and the higher the calorific value. Therefore, any biomass that is intended for thermochemical conversion should be allowed to dry.

\section{Effects of pretreatment on JSS and JFH biomasses}

The effects of acid and alkaline pretreatments on JSS and JFH biomasses were studied to bring to light how chemicals changed the biomass structure. Both $\mathrm{H}_{2} \mathrm{SO}_{4}$ and $\mathrm{NaOH}$ could effectively degrade hemicellulose and break or weaken the linkages between lignin and hemicellulose. Furthermore, $\mathrm{NaOH}$ could effectively remove or lessen lignin (depending on the concentration used), whereas $\mathrm{H}_{2} \mathrm{SO}_{4}$ removes more hemicellulose (Isaac et al., 2018).

During acid pretreatment, a significant reduction of the hemicellulosic component of JSS and JFH was hydrolysed, resulting in a mass loss of recovered biomass coupled with a consequential reduction of the cell wall thickness as compared to untreated biomasses. This observation corroborates Isaac et al., 2018 in their recent work. From their research findings, they submitted that acid pretreatment caused degradation of polymer linkages and selective lignin removal, as well as relocation in specific ultrastructural layers of the secondary cell walls. The solid loss recorded in JSS and JFH could be due to the degradation of cellulose as the hemicellulose was removed, thereby making the cellulose component more accessible to acid. 
Other researchers have reported similar findings (Xu et al., 2011; Hosgun and Bozan, 2020).

A significant change in the crystalline structure was noticed in the alkali pretreated JSS and JFH Page | 4134 as compared to untreated or raw samples. The improved crystallinity could be attributed to the aggregation of cellulose in $\mathrm{NaOH}$ solution (Xu et al., 2012) because increased temperature $\left(109{ }^{\circ} \mathrm{C}\right.$ in this case) favoured cellulose aggregation. A significant increase in crystallinity of the darkstained JSS was noticed. Alkali treatment of the JSS and JFH changes the cellulose structure via cellulose swelling that leads to a reduction in crystallinity and degree of polymerization of biomasses, by increasing their internal surface area (Iroba et al. 2013). The alkali treatment lessens lignin and hemicelluloses (the hemicelluloses polymers with more branches have stronger hydrophilic tendencies and are dissolved more easily in alkali media), thereby increasing the hydrophilicity of the JSS and JFH cellulose in alkali media, and this is ascribed to the abundance of its hydroxyl groups (-OH) because the induced chemical potential between the accessible hydroxyls of the hemicellulose, cellulose and polar water molecules leads to hydrogen bond formation. According to Gassan and Bledzki, 1998 , the bound water results in the separation of cellulose fibrils and hydro expansion. Also, pores were observed in the JSS and JFH biomass matrix which is ascribed to the swelling instituted by $\mathrm{NaOH}$, as these pores magnify the reactivity of the biomass matrix to any externally added material (Iroba et al. 2013). This swell is due to the disruption of intermolecular hydrogen bonds that binds cellulose molecules together (Oriez et al., 2020). Biomass swell is more pronounced in JFH than JSS. The addition of $\mathrm{NaOH}$ to lignocellulosic biomass causes swelling within the structure, the mechanism is the interaction of alkali and lignocellulosic biomass causing saponification of intermolecular ester bond linkages within the biomass (Iroba et al. 2013). These observations agree with previous studies on biomass structural deconstruction using the alkali pretreatment method (Iroba et al. 2013; Crawshaw et al., 2002; Yang et al., 2009). A solid loss was also observed in JSS and JFH biomasses after alkali pretreatment. This may be due to structural separation, disruption and disaggregation by the interaction between JSS and JFH biomass and $\mathrm{NaOH}$ solution at the elevated heating condition leading to the deconstruction or fractionation of the lignified matrix and hydrophilicity of cellulose. Two major reactions occurred during the alkali treatment of JSS and JFH biomasses. These two major reactions are solvation and saponification. During the pretreatment process, some portion of lignin is broken down, degraded and solubilized. Baruah et al., 2018 concluded that a saponification reaction takes place throughout the alkali pretreatment process which causes cleavage of the intermolecular ester linkages between hemicellulose and lignin and results in solubilisation of lignin and hemicellulose fragments in the alkali solution. Similar solid loss via alkali pretreatment has been reported (Xu et al., 2012; Iroba et al. 2013). Table 2 below summarises the yield and percentage loss of JSS and JFH biomasses during and after pretreatment.

Table 2: Biomass solid yield and percentage loss on pretreatment.

\begin{tabular}{|c|c|c|c|c|}
\hline \multirow{2}{*}{$\begin{array}{l}\text { Biomass } \\
\text { sample }\end{array}$} & \multicolumn{2}{|c|}{$\underline{\text { Biomass weight }}$} & \multirow{2}{*}{$\begin{array}{l}\text { Solid } \\
\text { yield } \\
(\%)\end{array}$} & \multirow{2}{*}{$\begin{array}{l}\text { Percentage loss } \\
\text { on pretreatment }\end{array}$} \\
\hline & $\begin{array}{l}\text { Before } \\
\text { pmt }\end{array}$ & $\begin{array}{l}\text { After } \\
\text { pmt }\end{array}$ & & \\
\hline $\begin{array}{l}\text { Acid } \\
\text { hydrolysed } \\
\text { JSS }\end{array}$ & 500 & 430 & 86.20 & 13.80 \\
\hline $\begin{array}{l}\text { Alkali } \\
\text { hydrolysed } \\
\text { JSS }\end{array}$ & 500 & 444 & 88.80 & 11.20 \\
\hline $\begin{array}{l}\text { Acid } \\
\text { hydrolysed } \\
\text { JFH }\end{array}$ & 500 & 325 & 65.00 & 35.00 \\
\hline $\begin{array}{l}\text { Alkali } \\
\text { hydrolysed } \\
\text { JFH }\end{array}$ & 500 & 265 & 53.00 & 47.00 \\
\hline
\end{tabular}


Where solid yield is calculated as

Solid Yield $=\frac{\text { Weight of the biomass after pretreatment }}{\text { Original weight of biomass feed }} \times 100$

Page | 4135

Percentage loss is calculated as the difference between the weight of the biomass before and after pretreatment divided by the original weight of the biomass X 100 .

\section{Pyrolysis of Jatropha curcas L. biomasses}

Table 3 show the results of slow pyrolysis of $1 \mathrm{Kg}$ of JSS and JFH at $450{ }^{\circ} \mathrm{C}$ using a fixed bed reactor is presented below

Table 3: Mass of bio-oil (viscous and aqueous layers) and bio-char recovered from $1 \mathrm{Kg}$ Jatropha biomass feedstock

\begin{tabular}{lcc}
\hline Pyrolysis products & \multicolumn{2}{c}{ Biomass sample (g) } \\
& JSS & JFH \\
\hline Condensate (raw) & 76.00 & 50.00 \\
Viscous phase & 127.00 & 117.00 \\
Aqueous phase & 152.00 & 250.00 \\
Biochar & & \\
& & \\
Condensate (acid hydrolysed) & & 16.00 \\
Viscous phase & 53.00 & 57.00 \\
Aqueous phase & 211.00 & 150.00 \\
Biochar & 398.00 & \\
& & \\
Condensate & & \\
hydrolysed) & (alkali & \\
Viscous phase & 70.00 & 51.00 \\
Aqueous phase & 169.00 & 200.00 \\
Biochar & 400.00 &
\end{tabular}

Yield of condensate (bio-oil viscous and aqueous layers) and bio-char

Pyrolysis products are condensate (which comprises of bio-oil viscous layer and aqueous phase), solid (in form of bio-char) and noncondensable gases. The product yields of pyrolysis of JSS and JFH at $450{ }^{\circ} \mathrm{C}, 1.14 \mathrm{~mm}$ particle size are presented in Table 3. Meanwhile, it is important to state that gas products resulting from the pyrolysis of JSS and JFH were not quantified in this work.
Table 4: Percentage by mass of bio-oil (viscous and aqueous layers) and bio-char recovered from Jatropha biomass feedstocks

\begin{tabular}{|c|c|c|c|}
\hline \multirow[t]{2}{*}{ Pyrolysis products } & & \multicolumn{2}{|c|}{ Biomass sample (\%) } \\
\hline & & JSS & JFH \\
\hline Condensate (raw) & & & \\
\hline Viscous phase & & 7.60 & 5.00 \\
\hline Aqueous phase & & 5.30 & 1.60 \\
\hline Bio-char & & 5.30 & 2.70 \\
\hline $\begin{array}{l}\text { Condensate } \\
\text { hydrolysed) }\end{array}$ & (acid & & \\
\hline Viscous phase & & 12.90 & 11.70 \\
\hline Aqueous phase & & 21.10 & 5.70 \\
\hline Biochar & & 16.90 & 5.10 \\
\hline $\begin{array}{l}\text { Condensate } \\
\text { hydrolysed) }\end{array}$ & (alkali & & \\
\hline Viscous phase & & 15.20 & 25.00 \\
\hline Aqueous phase & & 39.80 & 15.00 \\
\hline Biochar & & 40.00 & 20.00 \\
\hline
\end{tabular}

The yields of both untreated and pretreated JSS and JFH are relatively low. Untreated JSS pyrolysis yielded $15.20,39.80,40.00 \%$ and 25.00, 15.00 and $20.00 \%$ bio-char for raw, acid and alkali-treated JSS and JFH respectively. Raw (untreated) JSS gave a bio-oil yield of $7.60 \%$, which is higher than $5.00 \%$ in the untreated JFH. The acid-treated and alkali-treated JSS gave the same bio-oil yield of $5.30 \%$, which is lower compare to 1.60 and $2.70 \%$ in JFH. A critical look at Table 3 shows that the bio-oil aqueous layer yield is higher than the viscous layer: 12.90, 21.00 and $16.90 \%$ for raw, acid-treated and alkali-treated JSS and 11.70, 5.70 and $5.10 \%$ for raw, acid-treated and alkali-treated JFH respectively. This low yield reported in this study agrees with the report of Hsieh et al., 2015 where untreated rice straw pyrolysis yielded $47 \%$ biochar, $26 \%$ liquid with $4 \%$ bio-oil and $17 \%$ gas by mass and the acid-pretreated rice straw yielded $50 \%$ bio-char, $28 \%$ liquid with $2 \%$ bio-oil and $15 \%$ gas by mass. Generally, fast pyrolysis gives a greater bio-oil yield than slow pyrolysis.

Pretreatment with $\mathrm{H}_{2} \mathrm{SO}_{4}$ promoted increased biooil yield in JSS. The JSS bio-oil aqueous layer was $21.10 \%$ as compared to $12.90 \%$ and 16.90 
$\%$ in raw and alkali hydrolysed JSS. For the JFH, $5.70 \%$ bio-oil aqueous layer was higher than 5.10 $\%$ in alkali hydrolysed JFH.

Conversely, pretreatment with sodium hydroxide Page | 4136 promoted bio-char formation in JSS. Biochar produced from the pyrolysis of JSS was $40 \%$ as compared to 39.80 and $15.20 \%$ in the acid-treated and raw JSS respectively. For the JFH, the raw sample gave the highest biochar (25\%), followed by the alkali hydrolysed JFH (20\%). Therefore, acid pretreated samples produced bio-oil with high value-added chemicals. This observation in bio-oil yield and bio-char formation, especially in JSS pyrolysis with acid and alkali pretreated biomass is in agreement with findings on a similar biomass feedstock used for pyrolysis (Mohammed et al., 2016). Because a large percentage of lignin, which is an essential component of lignocellulosic biomass is removed during alkaline pretreatment, alkaline pretreatment cannot be considered suitable for a pyrolysis process. This observation corroborates Mohammed et al., 2016 in their recent findings on the effect of deionized water, sulphuric acid, and sodium hydroxide pretreatments of Napier grass on pyrolysis oil characteristics.

\section{GC-MS of Pyrolyzed Jatropha curcas L. biomass waste}

The compositions of bio-oil produced from raw and pretreated JSS and JFH were analyzed by GC-MS as listed in Tables 5-10. Identification of the GC-MS peaks was based in most cases on comparison with spectra of the NIST 1998 spectrum library. Only those separated products and the most abundant compound found are listed. Generally, bio-oil is a complicated organic compound that consists of water, acids and heterocyclic substances (Ji-lu et al., 2007), as these acids are the reason bio-oil pH is less than 3 . The most abundant compound found in the viscous bio-oil are phenols: 52.63, 21.43 and 8.33 $\%$ in the untreated (raw), acid hydrolysed, alkali hydrolysed JSS and paraffin respectively: 25.00,
33.33 and $35.71 \%$ in the untreated (raw), acid hydrolysed and alkali hydrolysed JFH respectively. The similarity in chemical composition was noticed in the raw, acid hydrolysed and alkali hydrolysed JSS with the presence of Phenol, 4-ethyl-2-methoxy-. Also, Hexadecanoic acid was present in the raw, acid hydrolysed and alkali hydrolysed JFH. The breakdown of the compounds detected in the Biooil produced from the six samples were classified into Paraffins, Olefins, Aromatics, Oxygencontaining compounds, Nitrogen-containing compounds, Phenols, Acids and Furan. The Oxygen-containing compounds (O.C.Cs) comprised of ester, alcohol, cyano and ketone while Nitrogen-containing compounds (N.C.Cs) consists of amide, nitrile, amine and nitroso- are as shown in Table $11-12$.

\section{Gas Chromatography- Mass Spectrometry (GC- MS) of the Bio-Oil}

The chromatograms of the raw JSS and JFH and the hydrolysed samples - acid and alkali are shown in Figs 1 - 6 .

Table 5-10 is a list of compounds identified in the untreated (raw), acid hydrolysed and alkali hydrolysed Bio-oils from JSS and JFH respectively and Table 8-9 shows the breakdown of compounds detected in terms of percentage in the samples. The compounds detected in the Biooil produced from the six samples were classified into Paraffins, Olefins, Aromatics, Oxygencontaining compounds, Nitrogen-containing compounds, Phenols, Acids and Furan. The Oxygen-containing compounds comprise ester, alcohol, cyano and ketone while Nitrogencontaining compounds consist of amide, nitrile, amine and nitroso-. The untreated (raw) JSS Biooil sample produced a relatively high percentage of Phenols (52.63\%), while the acid hydrolysed and alkali hydrolysed samples produced only $21.43 \%$ and $8.33 \%$ respectively. The Bio-oil from the alkali hydrolysed JSS produced $50 \%$ olefins, whereas olefins were absent in the raw 
and acid hydrolysed samples. A higher percentage of aromatics (42.86\%) were identified in the acid hydrolysed Bio-oil sample, while only $10.52 \%$ and nil were found in the untreated (raw) JSS and alkali hydrolysed JSS respectively. Furan (2 Page | 4137 Furancarboxaldehyde, 5-methyl-) was found only in the Bio-oil produced from the acid hydrolysed
JSS but absent in the untreated and alkali hydrolysed JSS.

\section{Fourier Transform Infrared Spectroscopy of the Bio-Oil / Analysis}

(FT-IR) The infrared spectra of the raw JSS, JFH and the hydrolysed samples - acid and alkali are shown in Figs 7-12.

Table 5: Chemical constituents of raw (untreated) Jatropha seed shell (JSS) detected by GC-MS

\begin{tabular}{|c|c|c|c|}
\hline $\mathrm{S} / \mathrm{N}$ & $\begin{array}{l}\text { Retention time } \\
\text { (min.) }\end{array}$ & Peak area $(\%)$ & Compound name \\
\hline 1. & 4.497 & 3.04 & Phenol \\
\hline 2. & 5.881 & 1.04 & Phenol, 2-methyl- \\
\hline 3. & 6.328 & 3.06 & Phenol, 4-methyl- \\
\hline 4. & 6.690 & 22.08 & Phenol, 2-methoxy- \\
\hline 5. & 8.818 & 3.36 & Phenol, 3-ethyl- \\
\hline 6. & 9.517 & 6.20 & Phenol, 2-methoxy-4-methyl- \\
\hline 7. & 12.337 & 25.32 & Phenol, 4-ethyl-2-methoxy- \\
\hline 8. & 14.996 & 2.02 & Phenol, 2,6-dimethoxy- \\
\hline 9. & 15.500 & 2.62 & Phenol, 2-methoxy-4-propyl- \\
\hline 10. & 16.432 & 1.39 & Butanamide \\
\hline 11. & 17.014 & 0.87 & $6 \mathrm{H}$-Pyrazolo[1,2-a][1,2,4,5] tetrazine hexahydro-2,3-dimethyl \\
\hline 12. & 17.098 & 0.78 & Benzyl alcohol, p-hydroxy-alpha.-[(methylamino) methyl]- \\
\hline 13. & 18.547 & 0.81 & $3,3^{1}$-Bis(1,2,4-oxadiazolyl)-5, $5^{1}$-diamine \\
\hline 14. & 18.663 & 2.73 & Phenol, 2-methoxy-4-(1-propenyl) \\
\hline 15. & 20.190 & 1.29 & Tetratetracontane \\
\hline 16. & 21.173 & 12.96 & Methyl 10-methyl-undecanoate \\
\hline 17. & 21.510 & 4.88 & 5-tert-Butylpyrogallol \\
\hline 18 & 32.493 & 1.71 & Hexacosylheptafluorobutyrate \\
\hline 19. & 36.911 & 3.81 & Tetradecanoic acid \\
\hline
\end{tabular}

Table 6: Chemical constituents of acid hydrolysed JSS detected by GC-MS

\begin{tabular}{|c|c|c|c|}
\hline $\mathrm{S} / \mathrm{N}$ & Retention time (min.) & Peak area $(\%)$ & Compound name \\
\hline 1. & 4.277 & 2.54 & 2-Furancarboxaldehyde, 5-methyl- \\
\hline 2. & 4.471 & 5.28 & Phenol \\
\hline 3. & 5.286 & 0.54 & Benzene,1-metyhl-2-(1-methylethyl)- \\
\hline 4. & 5.771 & 1.82 & Benzene,1-ethynyl-4-methyl- \\
\hline 5. & 5.868 & 5.18 & Phenol, 3-methyl- \\
\hline 6. & 6.321 & 17.49 & Phenol, 4-methyl- \\
\hline 7. & 8275 & 8.88 & Phenol, 2,4-dimethyl- \\
\hline 8. & 9.368 & 6.08 & Azulene \\
\hline 9. & 10.235 & 0.87 & 1H-Benzimidazole, 2-ethyl- \\
\hline 10. & 10.623 & 0.84 & Folic acid \\
\hline 11. & 12.343 & 4.65 & Phenol, 4-ethyl-2-methoxy- \\
\hline 12. & 12.958 & 11.06 & Naphthalene, 1-methyl- \\
\hline 13. & 13.547 & 3.55 & Naphthalene, 1-methyl- \\
\hline 14. & 15.759 & 0.59 & (1-Methylpenta-1,3-dienyl) benzene \\
\hline 15. & 16.154 & 1.38 & 1-Heptadecanamine \\
\hline 16. & 16.406 & 0.58 & Isobutyryl urea \\
\hline 17. & 16.923 & 1.74 & Naphthalene,1,3-dimethyl- \\
\hline 18. & 17.434 & 0.78 & Naphthalene,2,3-dimethyl- \\
\hline 19. & 17.570 & 0.53 & Naphthalene,2,3-dimethyl- \\
\hline 20. & 18.637 & 6.33 & Phenol, 2-methoxy-4-(1-propenyl) \\
\hline 21. & 19.258 & 0.53 & Ethanamine, 2-phenoxy- \\
\hline 22. & 19.879 & 2.23 & 3-Azabicyclo[3.2.2]nonane, 3-nitroso- \\
\hline 23. & 20.177 & 0.82 & d1-Alanylglycylglycine \\
\hline 24. & 21.173 & 9.63 & Dodecanoic acid \\
\hline 25. & 21.561 & 0.78 & Naphthalene,1,6,7-trimethyl- \\
\hline 26. & 23.644 & 1.15 & Pyrimidine,4-fluoro-6-dimethylamino- \\
\hline 27. & 28.489 & 3.55 & Methyl tetradecanoate \\
\hline 28. & 36.847 & 0.61 & 1-Heptadecanamine \\
\hline
\end{tabular}


Table 7: Chemical constituents of alkali hydrolysed JSS detected by GC-MS

\begin{tabular}{cccc}
\hline S/N & Retention time $(\min )$. & Peak area $(\%)$ & Compound name \\
\hline 1. & 12.636 & 8.70 & Phenol,4-ethyl-2-methoxy \\
2. & 19.873 & 4.74 & 1-Pentadecene \\
3. & 20.151 & 13.06 & Pentadecene \\
4. & 23.618 & 3.82 & 1-Tridecene \\
5. & 23.871 & 3.45 & Hexadecane \\
6. & 26.697 & 7.64 & 8-Heptadecene \\
7. & 26.924 & 5.97 & 1-Hexadecene \\
8. & 27.247 & 3.07 & 1-Nonadecene \\
9. & 27.493 & 9.19 & Heptadecane \\
10. & 31.025 & 1.08 & 1-Heptadecanamine \\
11. & 35.572 & 9.69 & Pentadecanenitrile \\
12. & 36.860 & 29.59 & Hexadecanoic acid \\
\hline
\end{tabular}

Table 8: Chemical constituents of raw (untreated) Jatropha fruit hull (JFH) detected by GC-MS

\begin{tabular}{cccc}
\hline S/N & Retention time (min.) & Peak area (\%) & Compound name \\
\hline 1. & 20.184 & 14.45 & Pentadecane \\
2. & 21.167 & 38.02 & Dodecanoic acid \\
3. & 28.489 & 17.10 & Methyl tetradecanoate \\
4. & 35.372 & 2.19 & 2,4-Bis(hydroxyamino)-5-nitropyrimidine \\
5. & 35.915 & 1.24 & 2,4-Dimethylamphetamine \\
6. & 36.368 & 1.15 & 4-Thia-1-azabicyclo[3.2.0]heptanes-2-carboxylic acid, 6- \\
& & & amino-3,3-dimethyl-7-oxo-, [2s-(2.alpha.,5.alpha., 6.beta.)] \\
& & & \\
7. & 36.905 & 24.62 & Hexadecanoic acid \\
8. & 38.102 & 1.24 & 2-Amino-1-(o-methoxylphenyl)propane \\
\hline
\end{tabular}

Table 9: Chemical constituents of acid hydrolysed JFH detected by GC-MS

\begin{tabular}{|c|c|c|c|}
\hline $\mathrm{S} / \mathrm{N}$ & $\begin{array}{l}\text { Retention time } \\
\text { (min.) }\end{array}$ & Peak area (min.) & Compound name \\
\hline 1. & 4.491 & 2.77 & Phenol \\
\hline 2. & 5.584 & 5.11 & 2-Cyclopenten-1-one, 2,3-dimethyl \\
\hline 3. & 5.875 & 5.28 & Phenol, 2-methyl- \\
\hline 4. & 6.347 & 4.49 & Phenol, 4-methyl- \\
\hline 5. & 8.281 & 25.01 & Phenol, 2,4-dimethyl- \\
\hline 6. & 11.781 & 2.69 & 2,4-Dimethylanisole \\
\hline 7. & 12.344 & 5.84 & Phenol, 4-ethyl-2-methoxyl- \\
\hline 8. & 12.777 & 2.59 & Tridecane \\
\hline 9. & 16.134 & 1.86 & 5-Tetradecane, $(\mathrm{E})$ - \\
\hline 10. & 16.419 & 7.15 & Tetradecane \\
\hline 11. & 19.905 & 2.46 & 1-Pentadecene \\
\hline 12. & 20.184 & 6.19 & Pentadecane \\
\hline 13. & 21.477 & 2.86 & Benzene, $1,1^{1}$-ethylidenebis \\
\hline 14. & 23.916 & 3.78 & Hexadecane \\
\hline 15. & 27.512 & 4.40 & Heptadecane \\
\hline 16. & 27.920 & 0.81 & Phenol, 2,6-dimethoxy-4-(2-propenyl)- \\
\hline 17. & 28.625 & 5.40 & 4-Nonene, 5-butyl- \\
\hline 18. & 31.057 & 2.75 & Octadecane \\
\hline 19. & 35.398 & 3.16 & Tetradecane \\
\hline 20. & 35.618 & 1.78 & $\begin{array}{c}\text { 3-Ethyl-4-hydroxy-4,6,6-trimethylhexahydropyrimidin-2-thione } \\
\text { Hexadecanoic acid }\end{array}$ \\
\hline 21. & 36.892 & 3.63 & \\
\hline
\end{tabular}


Table 10: Chemical constituents of alkali hydrolysed JFH detected by GC-MS

\begin{tabular}{cccc}
\hline S/N & Retention time (min.) & $\begin{array}{c}\text { Peak area } \\
\text { (min.) }\end{array}$ & Compound name \\
\hline 1. & 5.571 & 1.63 & Isopropenylcyclopropane \\
2. & 6.328 & 2.29 & Phenol, 3-methyl- \\
3. & 6.690 & 5.35 & Mequinol \\
4. & 8.255 & 12.78 & Phenol, 3,5-dimethyl- \\
5. & 12.318 & 7.43 & O-Methoxy-.alpha.-methyl benzyl alcohol \\
6. & 19.867 & 1.51 & Pentadecane \\
7. & 20.145 & 3.34 & Benzene, $1,1^{1}$-ethylidenebis- \\
8. & 21.451 & 1.91 & 3-Trifluoroacetoxytetradecane \\
9. & 27.241 & 1.69 & Heptadecane \\
10. & 27.487 & 3.35 & Ethyl dibromoacetate \\
11. & 28.567 & 1.75 & 11-Octadecenoic acid \\
12. & 33.198 & 47.34 & Octadecenoic acid \\
13. & 36.310 & 3.82 & Hexadecanoic acid \\
14. & 36.840 & 5.79 &
\end{tabular}

Table 11: Breakdown of compounds detected in terms of percentage in the untreated (raw), acid hydrolysed and alkali hydrolysed JSS

\begin{tabular}{ccccc}
\hline S/N & Compounds detected & \multicolumn{3}{c}{ Percentage of Compounds detected (\%) } \\
& & Raw (untreated) & Acid hydrolysed & Alkali hydrolysed \\
\hline 1. & Paraffins & 5.26 & 0.00 & 16.67 \\
2. & Olefins & 0.00 & 0.00 & 50 \\
3. & Aromatics & 10.52 & 43.86 & 0.00 \\
4. & O.C.Cs & 21.05 & 3.57 & 8.33 \\
5. & N.C.Cs & 5.26 & 17.86 & 8.33 \\
6. & Phenols & 52.63 & 21.43 & 8.33 \\
7. & Acids & 5.26 & 10.71 & 8.33 \\
8. & Furan & 0.00 & 3.57 & 0.00 \\
\hline
\end{tabular}

Table 12: Breakdown of compounds detected in terms of percentage in the untreated (raw), acid hydrolysed and alkali hydrolysed JFH

\begin{tabular}{ccccc}
\hline S/N & Compounds & \multicolumn{3}{c}{ Percentage of Compounds detected (\%) } \\
& detected & Raw (untreated) & Acid hydrolysed & Alkali hydrolysed \\
\hline 1. & Paraffins & 25.00 & 33.33 & 35.71 \\
2. & Olefins & 0.00 & 14.29 & 0.00 \\
3. & Aromatics & 25.00 & 14.29 & 7.14 \\
4. & O.C.Cs & 12.50 & 4.76 & 14.29 \\
5. & N.C.Cs & 12.50 & 0.00 & 0.00 \\
6. & Phenols & 0.00 & 28.57 & 14.29 \\
7. & Acids & 25.00 & 4.76 & 14.29 \\
8. & Furan & 0.00 & 0.00 & 0.00 \\
\hline
\end{tabular}




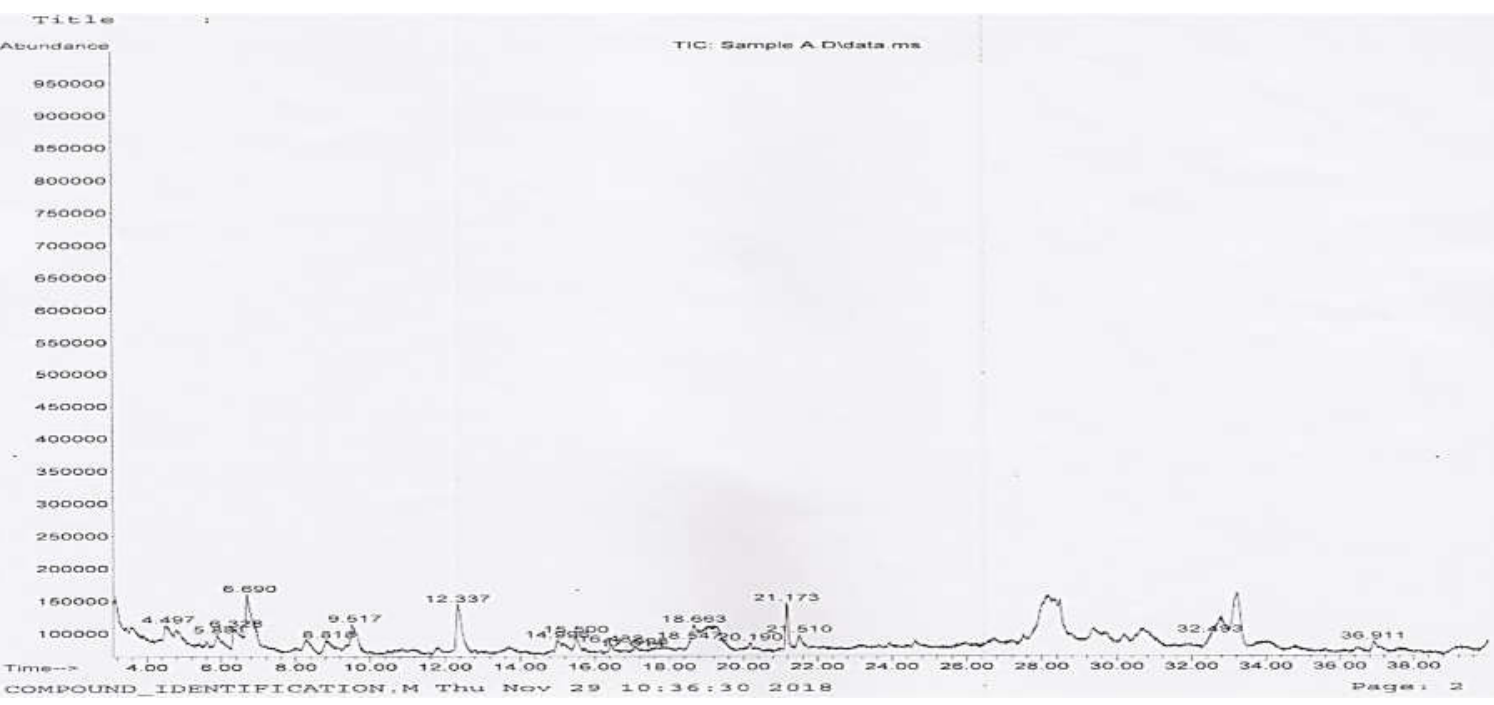

Fig 1: GC-MS chromatograms of the raw (untreated) JSS

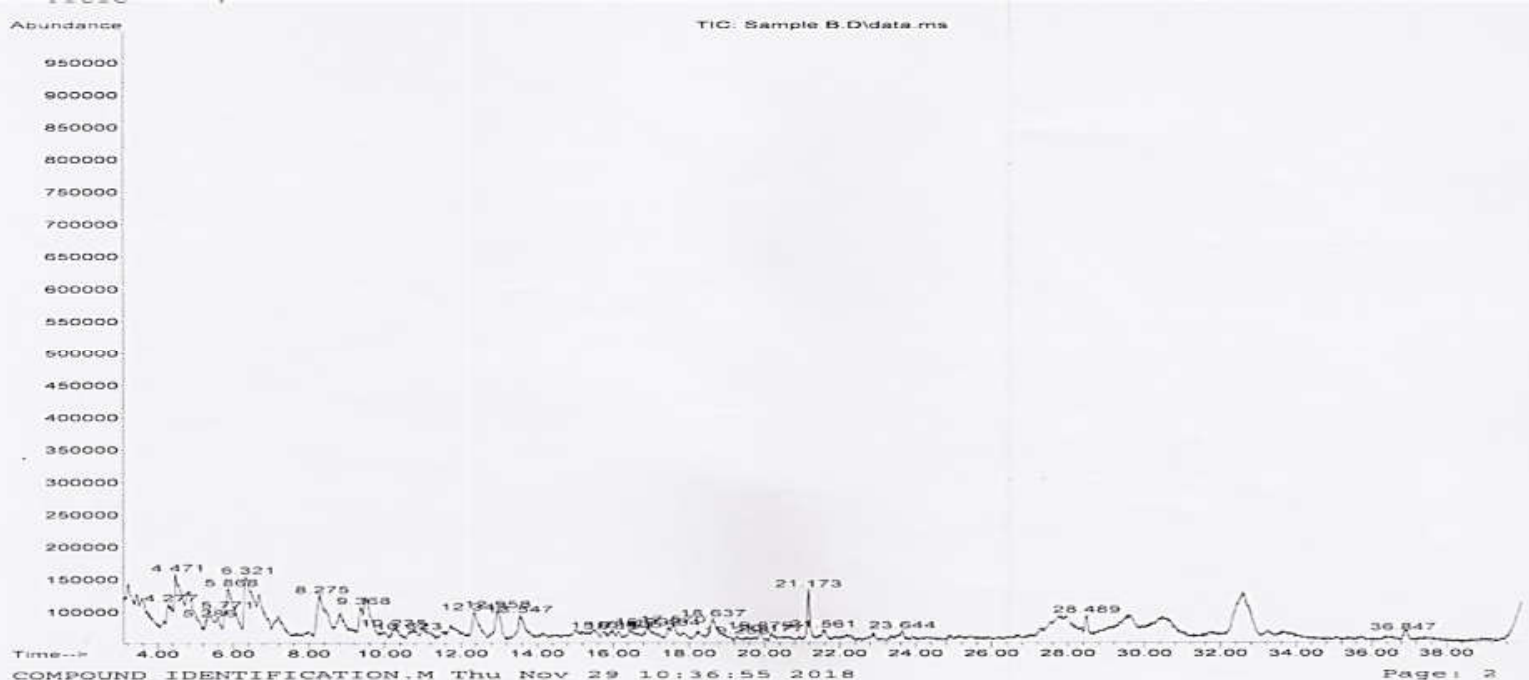

Fig 2: GC-MS chromatograms of the acid hydrolysed JSS

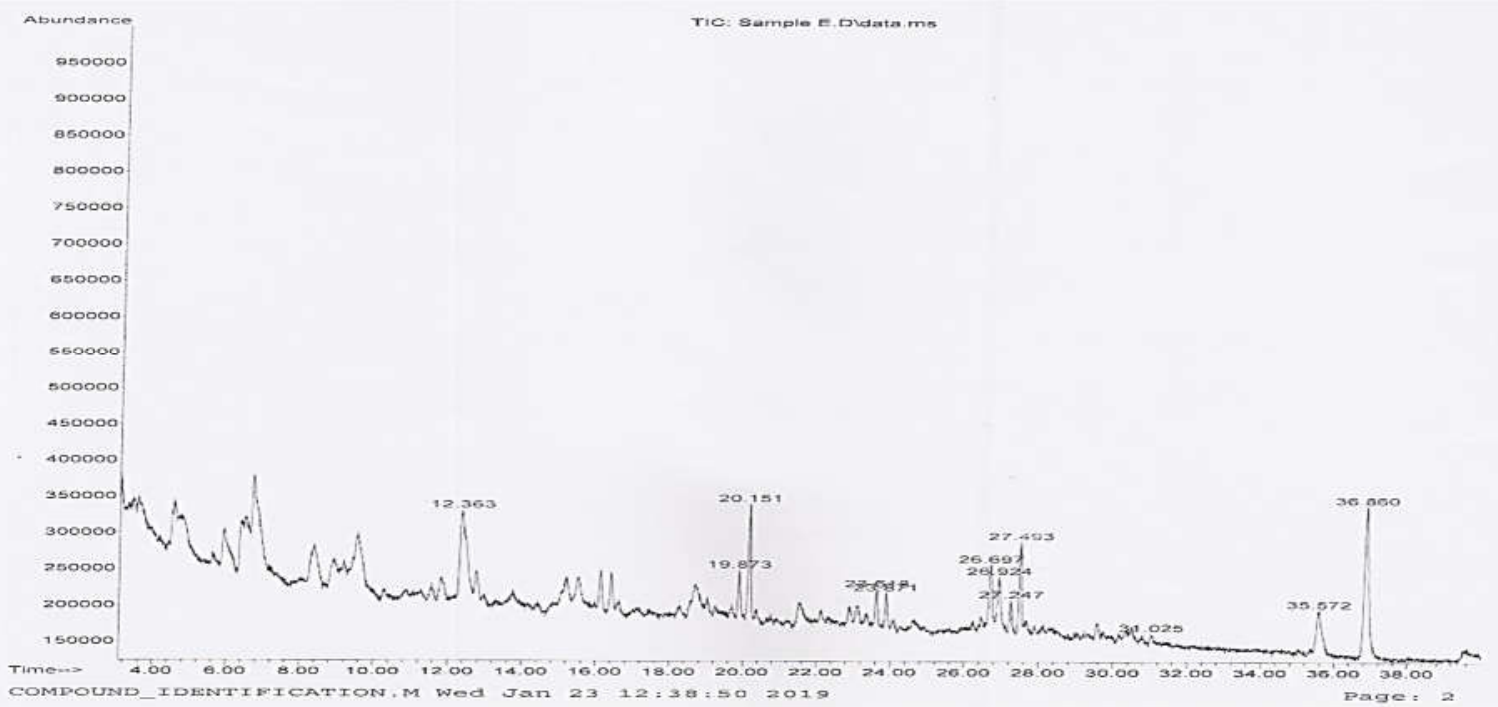

Fig 3: GC-MS chromatograms of the alkali hydrolysed JSS

Nig. J. Pure \& Appl. Sci. Vol. 34 (Issue 2): 4126-4152 


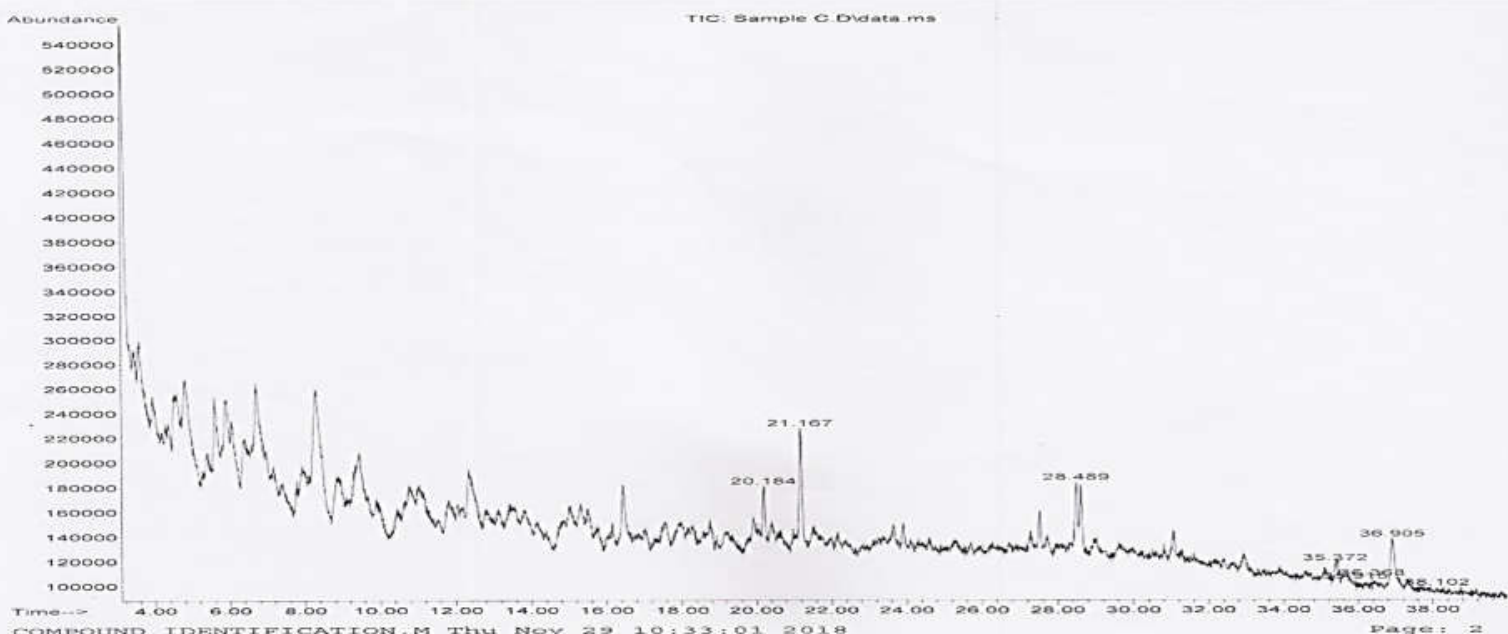

Fig 4: GC-MS chromatograms of the raw (untreated) JFH

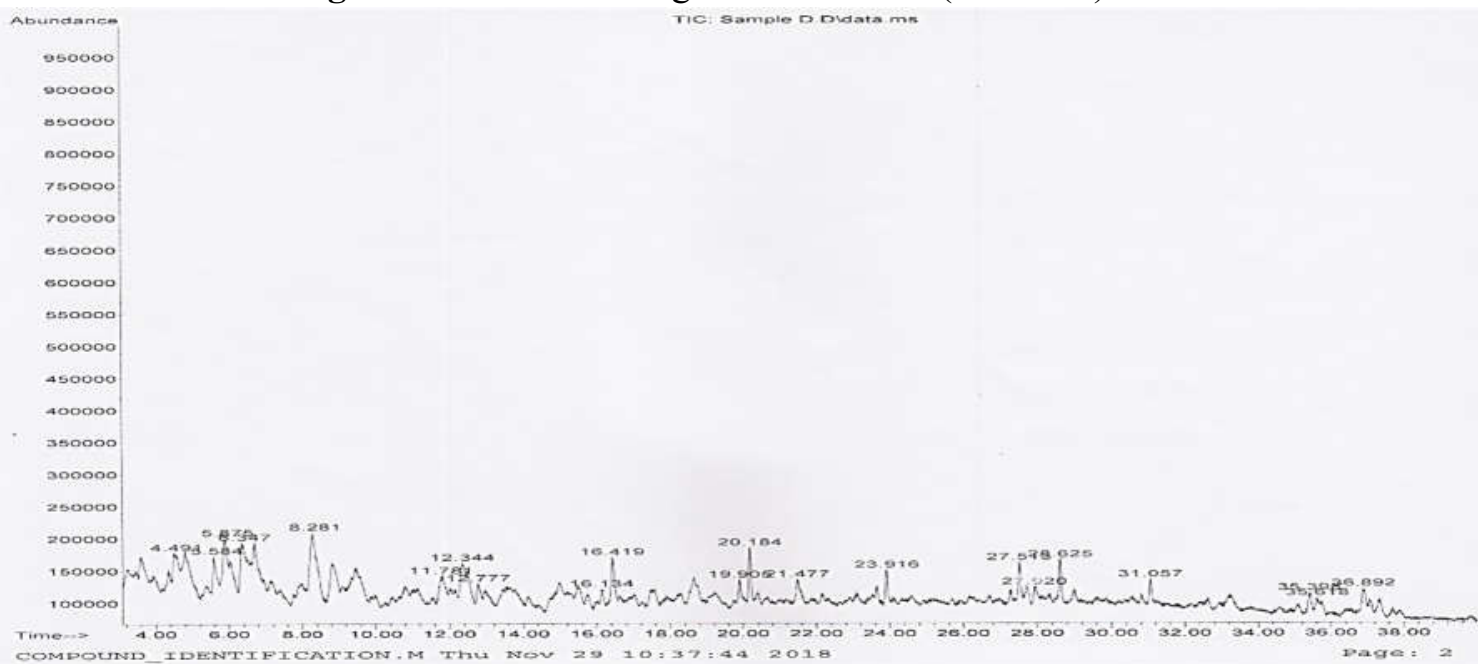

Fig 5: GC-MS chromatograms of the acid hydrolysed JFH

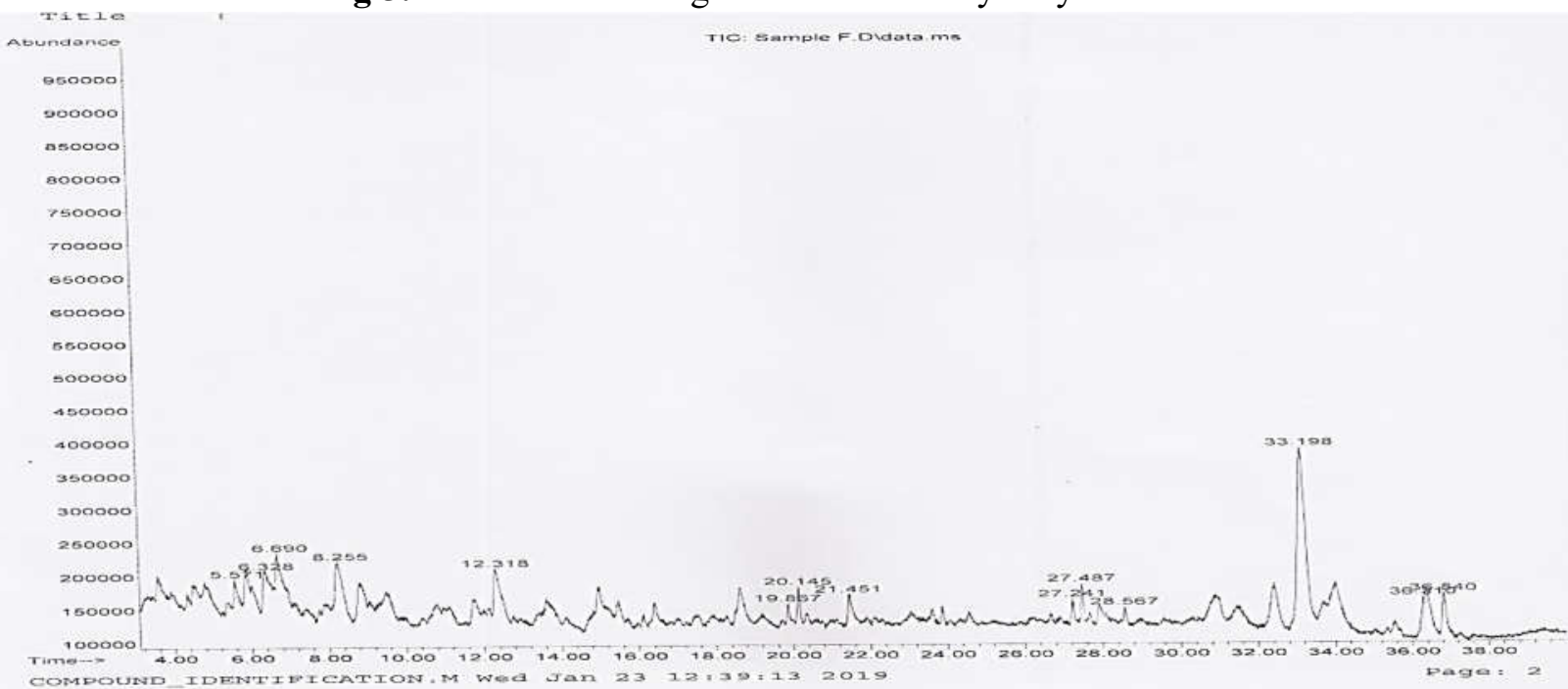

Fig 6: GC-MS chromatograms of the alkali hydrolysed JFH 


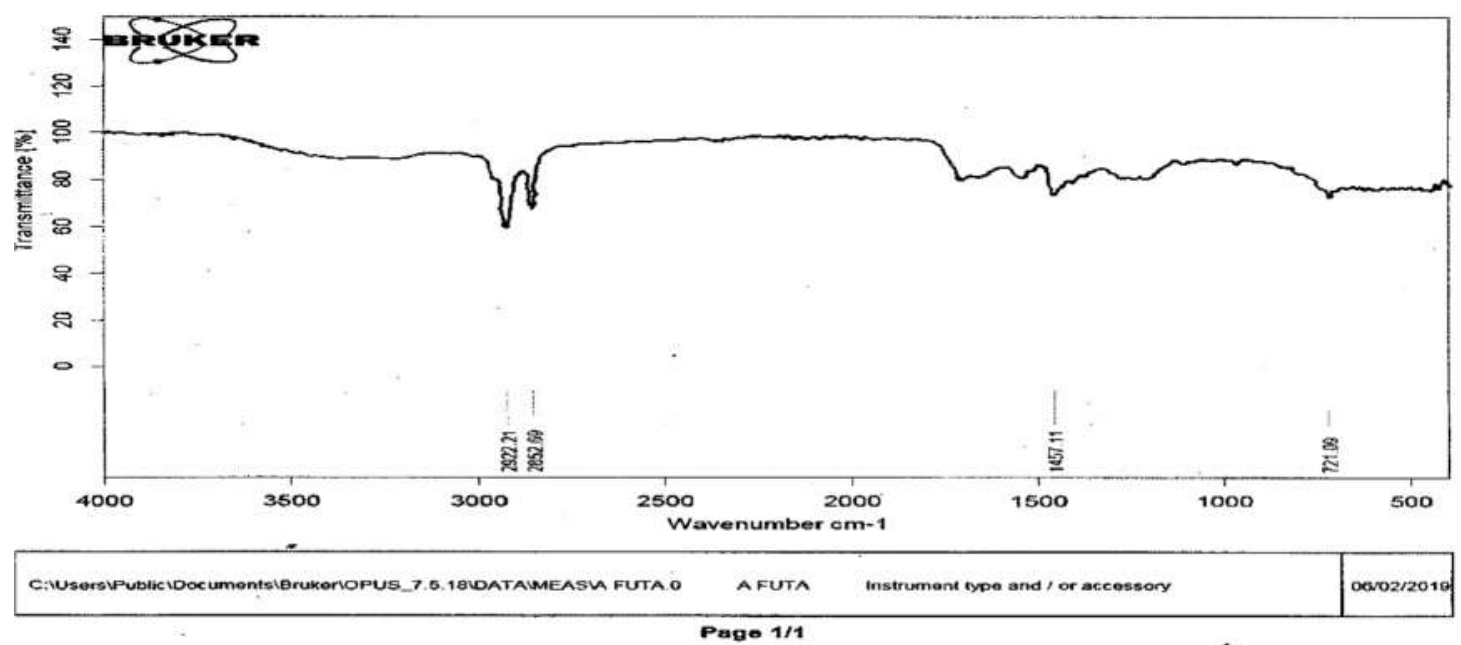

Fig. 7: FT-IR Spectrum for raw (untreated) JSS Bio-oil

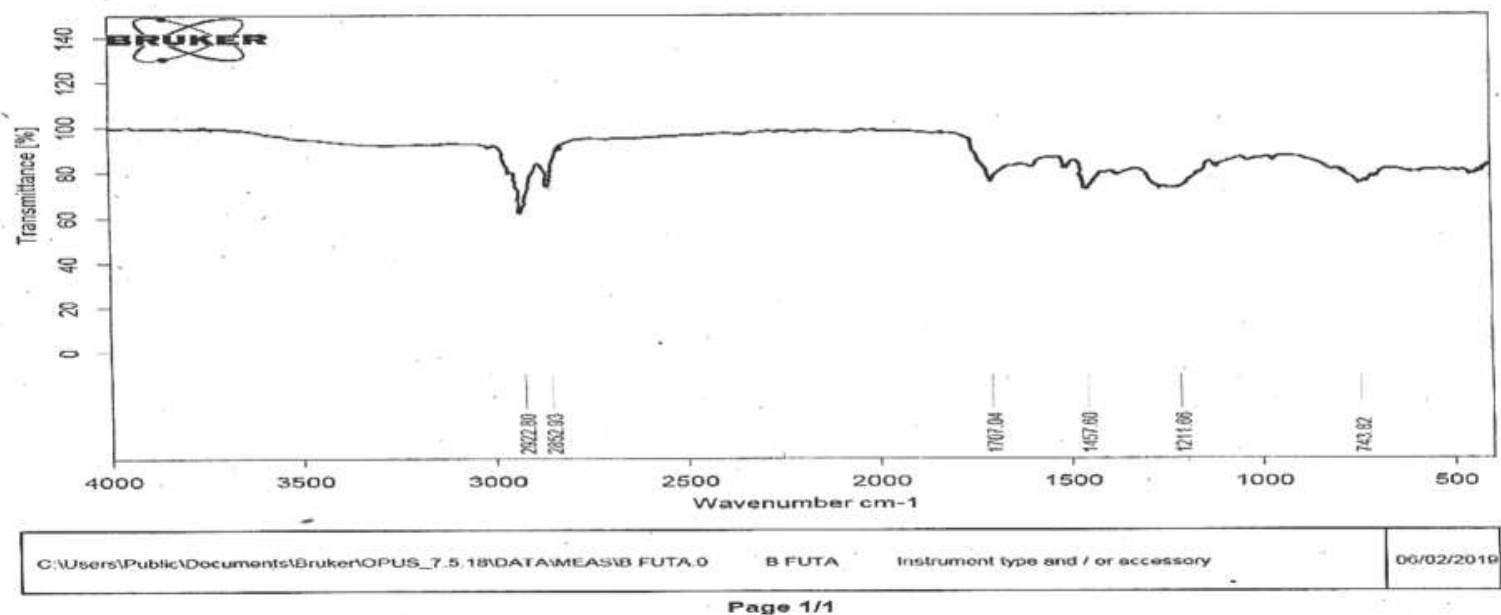

Fig. 8: FT-IR spectrum for acid hydrolysed JSS Bio-oil

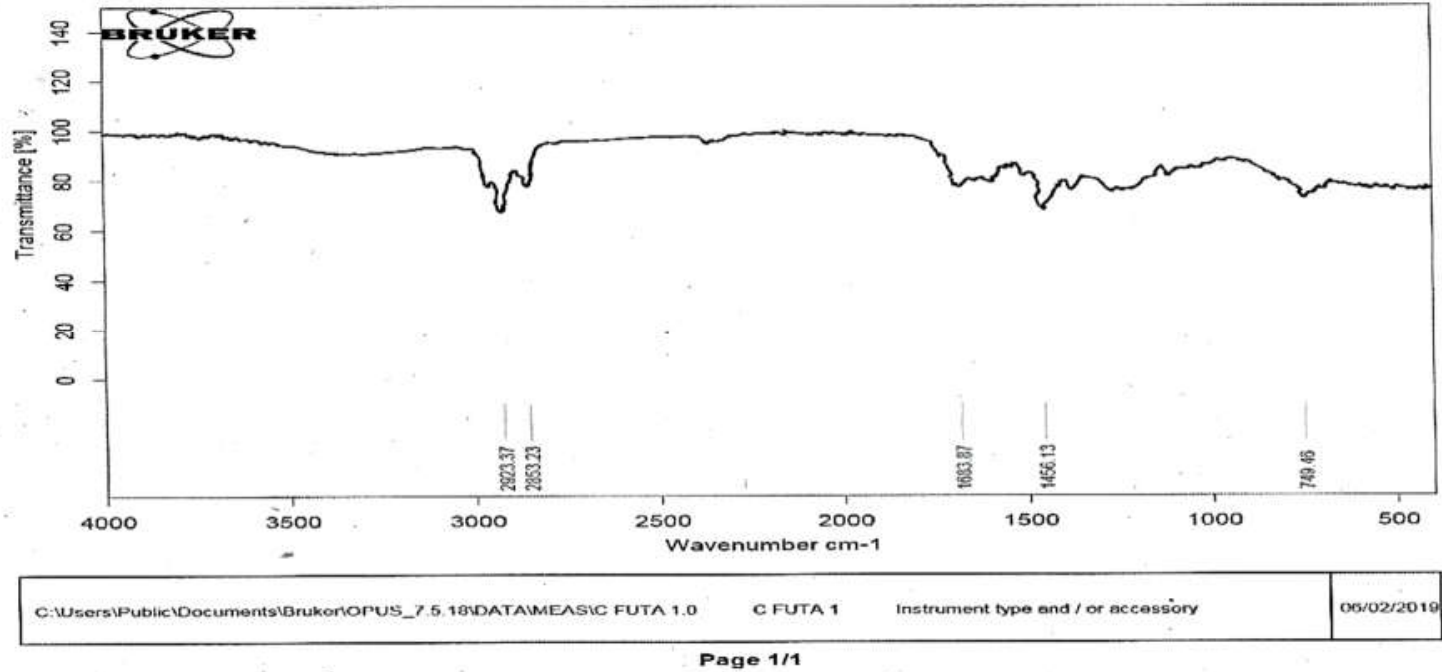

Fig. 9: FT-IR spectrum for alkali hydrolysed JSS Bio-oil 


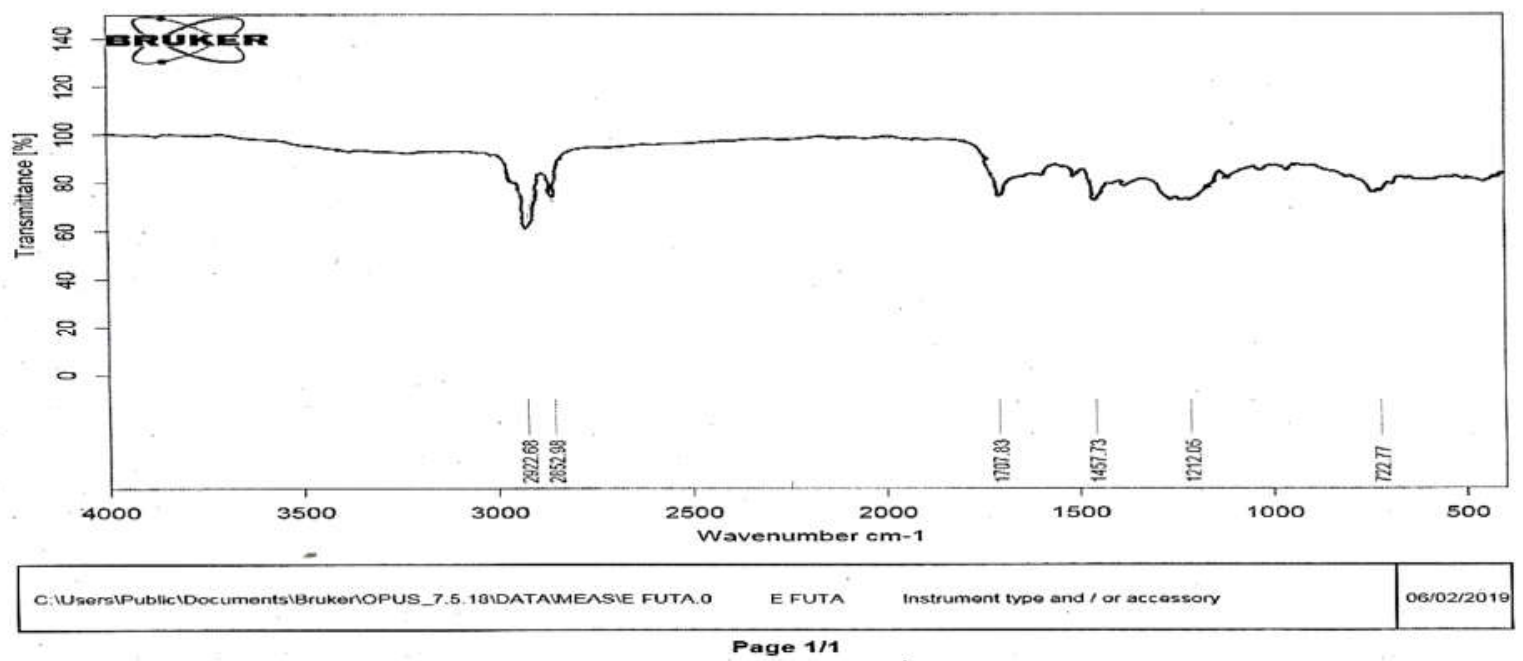

Fig. 10: FT-IR spectrum for raw (untreated) JFH Bio-oil

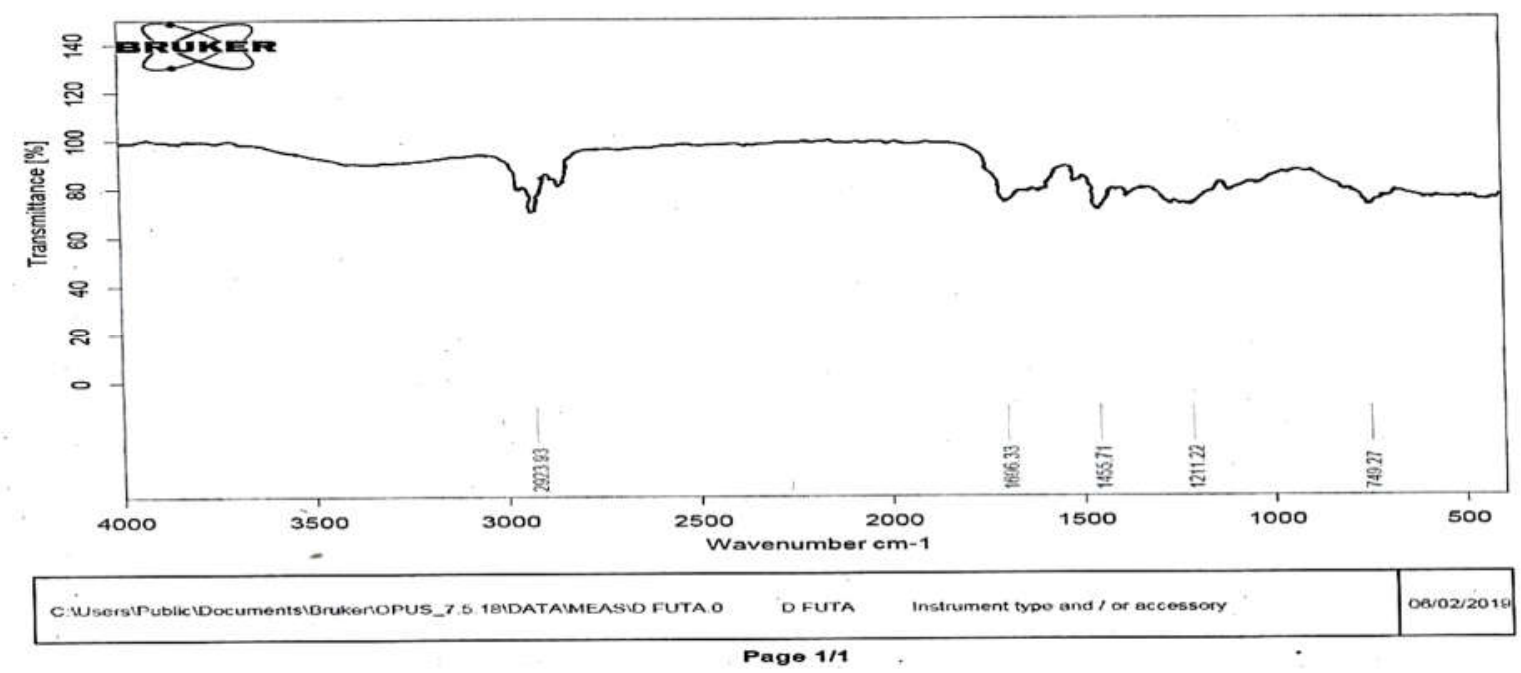

Fig.11: FT-IR spectrum acid hydrolysed JFH Bio-oil

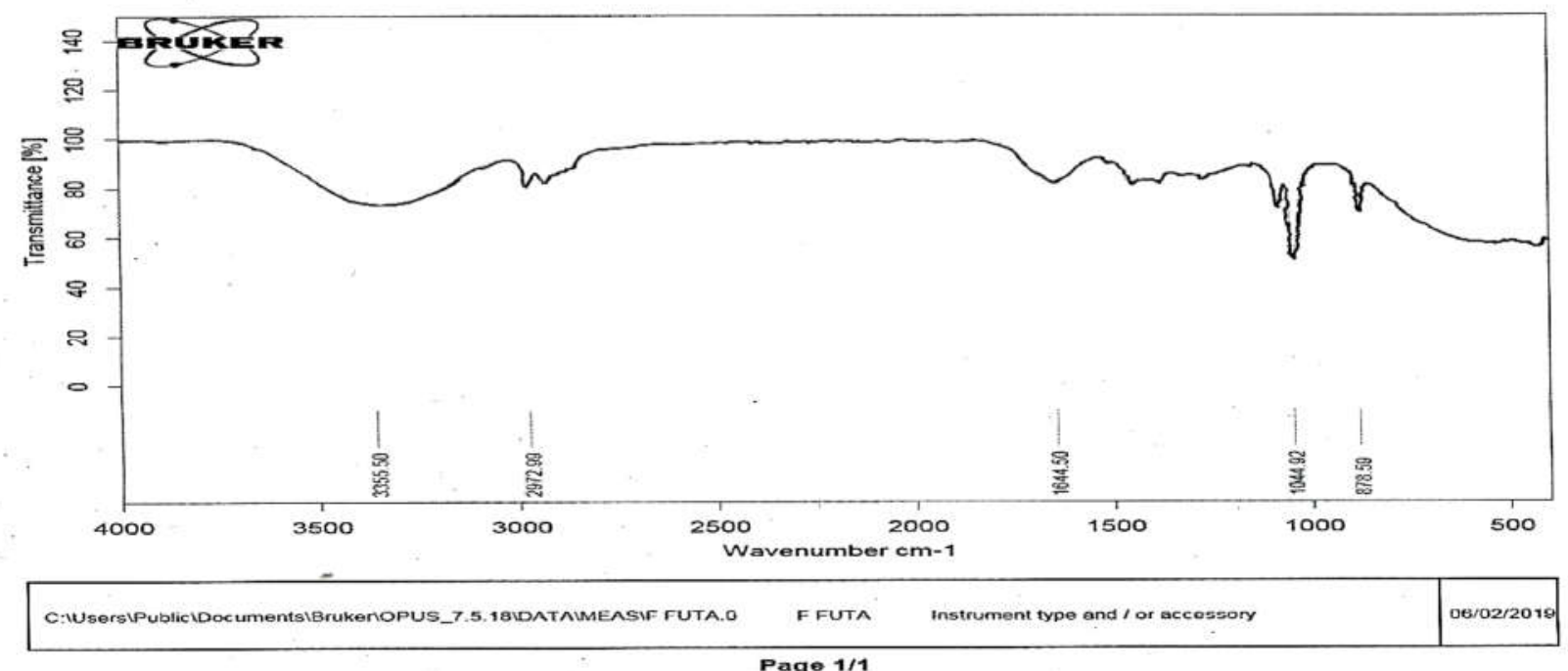

Fig.12: FT-IR spectrum alkali hydrolysed JFH Bio-oil

Nig. J. Pure \& Appl. Sci. Vol. 34 (Issue 2): 4126-4152 
Table 10: Characteristics IR absorption frequencies of Organic functional groups of raw, acid and alkali hydrolysed Jatropha curcas L. seed shell (JSS)

Characteristics absorption $\left(\mathrm{cm}^{-1}\right)$

Raw Acid hydrolysed Alkali

hydrolysed

Page | $4 1 4 4 \longdiv { 1 . 2 9 2 2 . 2 1 \quad 2 9 2 2 . 8 0 }$

2. $2852.69 \quad 2852.93$

3. - $\quad 1707.04$

4. $1457.11 \quad 1457.60$

5. $\quad-\quad 1211.66$

6. $721.09 \quad 743.82$
Functional group/Type of vibration

2922.68

2852.98

1707.83

1457.73

1212.05

722.77

$\mathrm{C}-\mathrm{H}$ (alkane)/stretching
$\mathrm{C}-\mathrm{H}$ (methylene)/asymmetrical stretching
$\mathrm{C}=\mathrm{O}$ (ketone, aliphatic and open chain
$\left.\mathrm{R}_{2} \mathrm{CO}\right) /$ stretching
$\mathrm{C}=\mathrm{C}($ aromatic) /stretching
$\mathrm{C}-\mathrm{O}$ (ethers, esters)/ stretching
$\mathrm{C}-\mathrm{H}$ (cis distributed olefins = $\mathrm{C}-\mathrm{H}$ and -
$\left(\mathrm{CH}_{2}\right) \mathrm{n}$ methylene groups ( cis distributed
alkenes and olefins / out-of-plane bending
overlapping rocking and out-of-plane bending
vibration of methylene and alkene

Table 11: Characteristics IR absorption frequencies of Organic functional groups of raw, acid and alkali hydrolysed Jatropha curcas L. fruit hull (JFH)

\begin{tabular}{|c|c|c|c|}
\hline \multicolumn{3}{|c|}{ Characteristics absorption $\left(\mathrm{cm}^{-1}\right)$} & \multirow{2}{*}{ Functional group/Type of vibration } \\
\hline Raw & ydrolysed & Alkali hydrolysed & \\
\hline 1. & 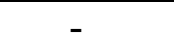 & 3355.50 & $\mathrm{O}-\mathrm{H} /$ stretching $(\mathrm{H}-$ bonded$)$ \\
\hline 2. 2923.37 & 2923.93 & 2972.99 & C-H (alkane)/stretching \\
\hline 3. 2853.23 & - & - & $\mathrm{C}-\mathrm{H}$ (methylene)/ asymmetrical stretching \\
\hline 4. 1683.87 & 1693.33 & - & $\mathrm{C}=\mathrm{O}$ (ketone, conjugated $)$ \\
\hline- & & 1644.50 & $\mathrm{C}=\mathrm{C}$ (alkene $) /$ stretching \\
\hline 5. 1456.13 & 1455.71 & - & $\mathrm{C}=\mathrm{C}$ (aromatic) $/$ stretching \\
\hline - & 1211.22 & - & $\mathrm{C}-\mathrm{O}$ (ether, esters)/ stretching \\
\hline - & - & 1044.92 & $\mathrm{C}-\mathrm{O}-\mathrm{C}$ (ether)/antisymmetric stretching \\
\hline - & - & 878.59 & $\mathrm{C}-\mathrm{H}$ (arene)/ out-of-plane bending vibration \\
\hline 6. 749.46 & 749.27 & - & $\begin{array}{l}\mathrm{C}-\mathrm{H} \text { (cis distributed olefins }=\mathrm{C}-\mathrm{H} \text { and }-\left(\mathrm{CH}_{2}\right) \mathrm{n} \\
\text { methylene groups (cis distributed alkenes and } \\
\text { olefins }\end{array}$ \\
\hline
\end{tabular}

The Bio-oil obtained from the raw and treated $J$. curcas $\mathrm{L}$. biomass was characterized by infrared spectroscopy (FT-IR). The infrared spectra of the raw, acid hydrolysed and alkali hydrolysed JSS and JFH are shown in Figs 7-12. The reflectance bands were used to identify the main functional groups present. The band assignments of the spectra areas contained in Biomass pyrolysis previous studies (Wong et al., 1998; Capunitan and Capareda, 2013; Mohammed et al., 2014;
Sutrisno and Hidayat, 2016; Shah et al., 2016a; Shah et al.,2016b; Dhanavath et al., 2017;). The summary of the characteristics IR absorption frequencies as well as the type of vibration of Organic functional groups of raw, acid and hydrolysed JSS and JFH biomasses are itemized in Tables 10 and 11.

The results of the raw, acid hydrolysed and alkali hydrolysed JSS at 2922.21, 2922.80 and 2922.68 $\mathrm{cm}^{-1}$ respectively indicates (C-H) alkane 
stretching vibration while strong sharp peaks at 2852.69, 2852.93 and $2852.98 \mathrm{~cm}^{-1}$ respectively also indicate $(\mathrm{C}-\mathrm{H})$ methylene asymmetrical stretching. Distinctive strong peaks at 1707.04 and $1707.03 \mathrm{~cm}^{-1}$ for acid and alkali hydrolysed

Page | 4145 JSS respectively correspond to $(\mathrm{C}=\mathrm{O})$ ketone, aliphatic and open-chain stretching. Meanwhile, this distinctive peak was not observed in the raw JSS. The strong intensity due to stretching vibration of $\mathrm{C}=\mathrm{C}$ (aromatic) appear at 1457.11, 1457.60 and $1457.73 \mathrm{~cm}^{-1}$ for raw, acid hydrolysed and alkali hydrolysed samples respectively. Absorptions possibly due to $\mathrm{C}-\mathrm{O}$ vibrations from carbonyl components (ether, ester) occur at 1211.66 and $1212.05 \mathrm{~cm}^{-1}$ for acid and alkali hydrolysed samples respectively and this was observed to be absent in the raw JSS sample. The bands at 721.09, 743.82 and $722.77 \mathrm{~cm}^{-1}$ for raw, acid and alkali hydrolysed JSS samples respectively are related to an out-ofplane bending vibration of methylene and alkene assigned to $\mathrm{C}-\mathrm{H}$ (cis distributed olefins, $=\mathrm{C}-\mathrm{H}$ and $-\left(\mathrm{CH}_{2}\right)$ n methylene groups (cis distributed alkenes and olefins). The raw, acid and alkali hydrolysed JSS showed similar functional groups ( $\mathrm{C}-\mathrm{H}$ (alkane), $\mathrm{C}-\mathrm{H}$ (methylene), $\mathrm{C}=\mathrm{C}$ (aromatic) and $\mathrm{C}-\mathrm{H}$ (cis distributed olefins $=\mathrm{C}-\mathrm{H}$ and $-\left(\mathrm{CH}_{2}\right)$ n methylene groups ( cis distributed) alkenes and olefins. However, $\mathrm{C}=\mathrm{O}$ (ketone, aliphatic and open-chain $\mathrm{R}_{2} \mathrm{CO}$ and $\mathrm{C}-\mathrm{O}$ (ether, esters) were observed in the pretreated JSS. These functional groups were not observed in the raw (unpretreated) JSS. The FT-IR results showed that the raw JSS is deficient in oxygenated species. It can be concluded that both acid and alkali pretreatment enhances the emergence of more functional groups in the Biooil produced from the JSS. The appearance or disappearance of the functional group was due to the conversion of one class of compound into another class of compound due to dehydrogenation, dehydration and cracking during pyrolysis (Shah et al., 2016).
The bands at 2923.37, 2923.93 and $2972.99 \mathrm{~cm}^{-1}$ for raw, acid hydrolysed and alkali hydrolysed JFH are related to $\mathrm{C}-\mathrm{H}$ stretching vibrations, signalling the presence of alkanes. A peak at $2853.23 \mathrm{~cm}^{-1}$ for the raw JFH corresponds to $\mathrm{C}-$ $\mathrm{H}$ (methylene) asymmetrical stretching vibration. The band at $1683.87 \mathrm{~cm}^{-1}$ and $1696.33 \mathrm{~cm}^{-1}$ for raw and acid hydrolysed JFH corresponds to $\mathrm{C}=\mathrm{O}$ stretching while a band at $1644.50 \mathrm{~cm}^{-1}$ for alkali hydrolysed sample can be assigned to $\mathrm{C}=\mathrm{C}$ (alkene) stretching. A band at $1456.13 \mathrm{~cm}^{-1}$ and $1455.71 \mathrm{~cm}^{-1}$ for raw and acid hydrolysed JFH is assigned to $\mathrm{C}=\mathrm{C}$ (aromatic) stretching. A distinctive band at 1211-22 $\mathrm{cm}^{-1}$ for acid hydrolysed JFH corresponds to $\mathrm{C}-\mathrm{O}$ (ethers, esters) stretching vibration and another at $1044.92 \mathrm{~cm}^{-1}$ for alkali hydrolysed JFH corresponds to $\mathrm{C}-\mathrm{O}-\mathrm{C}$ (ether) antisymmetric stretching. A differential strong band peak at $3355.50 \mathrm{~cm}^{-1}$ for alkali hydrolysed JFH is assigned to $\mathrm{O}-\mathrm{H}$ (H-bonding) stretching. A strong sharp peak at $878.59 \mathrm{~cm}^{-1}$ for the alkali hydrolysed JFH corresponds to $\mathrm{C}-\mathrm{H}$ (arene) outof-plane bending vibration. Medium peaks at $749.46 \mathrm{~cm}^{-1}$ and $749.27 \mathrm{~cm}^{-1}$ for raw and acid hydrolysed JFH respectively are assigned to $\mathrm{C}-\mathrm{H}$ (cis distributed olefins, $=\mathrm{C}-\mathrm{H}$ and $-\left(\mathrm{CH}_{2}\right) \mathrm{n}$ methylene group out-of-plane bending overlapping rocking and out-of-plane bending vibration of methylene and alkene. Also, the result of the alkali hydrolysed JFH indicates (O$\mathrm{H})$ alcohol stretching at $3355.50 \mathrm{~cm}^{-1}$. This $\mathrm{O}-\mathrm{H}$, which is a differential broad peak may be due to the presence of water content in the Bio-oil produced through the alkali hydrolysis process. The differential peak was not observed in the raw and the acid hydrolysed JFH Bio-oil.

\section{Scanning Electron Microscopy (SEM) of the raw and hydrolysed samples used for Bio-oil Production}

As biomass is being pretreated, all the surface characteristics of the hydrolysate change progressively. Scanning electron microscope 
(SEM) micrographs of pretreated and untreated Jatropha curcas L. waste (JSS and JFH) were taken to study the changes in surface characteristics of the biomass. The images obtained at magnifications X1000 and X2000 are Page | 4146 shown in Figs 13-14.

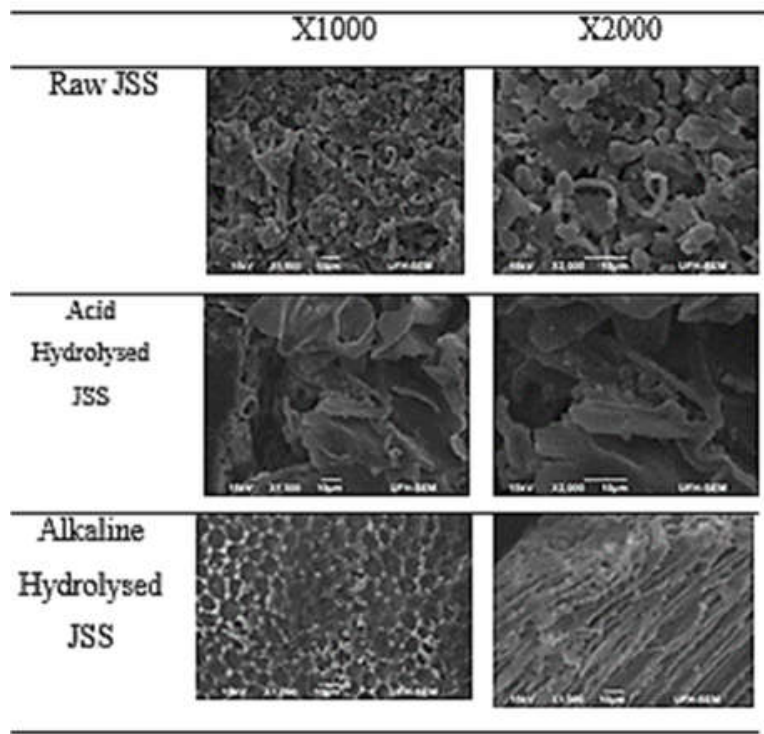

Fig. 13: SEM images of the raw (untreated), acid hydrolysed and alkali hydrolysed JSS at X1000 and X2000 magnifications

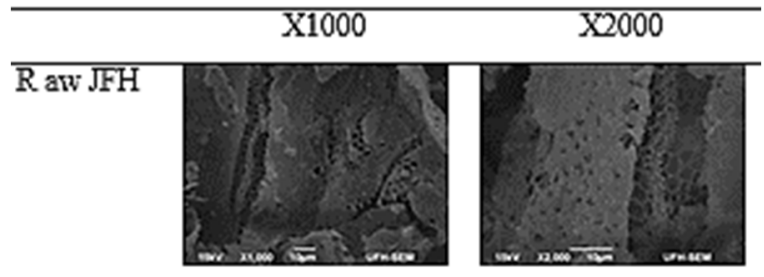

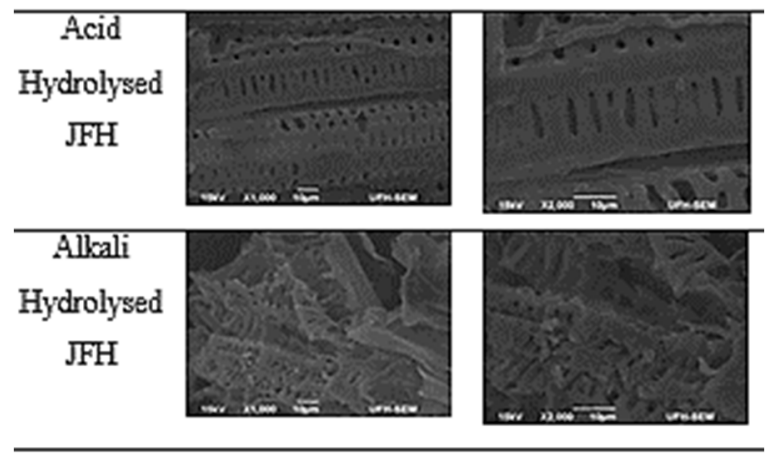

Fig.14: SEM images of the raw (untreated) JFH, acid hydrolysed and alkali hydrolysed JFH at X1000 and X2000 magnifications
For the JSS, the SEM images clearly showed that the raw (untreated) revealed a rigid and highly compact structure whereas in acid and alkali pretreated JSS, there is a reasonable surface modification and the biomasses showed the opening of the cellulose fibrils, thereby increasing the porosity of the biomass. Meanwhile, pores present in the acid and alkalitreated JSS may have been due to substantial removal of the hemicelluloses and lignin respectively. The possible reason for surface modification may be fractionation/breaking of lignin bond caused by $\mathrm{NaOH}$ activity in alkali pretreated JSS and JFH. According to Tsegaye et al., 2016, the lignin-hemicellulose-cellulose matrix is cloven and destroyed by excited carboxyl groups produced by saponification of ester linkage on the xylan backbone which gives rise to hydrogen bonds disruption in the cellulose. The raw JSS image illustrates a large and highly dense structure which are coarsely grained with a larger contact area and increased roughness. It also disclosed that the particles are multidispersed with significant pore aperture. Nevertheless, the acid and alkali hydrolysed JSS showed short fibrous and porous structures from the initial connected structure and are fully exposed, thus broadening the external surface area and porosity. In alkali hydrolysed JSS image, the pores present may be due to high levels of removed lignin, which is in tandem with the observation of Wi et al., 2015 in their similar work using alkali pretreatment.

Differences in morphology could be observed in the raw (untreated) and treated (hydrolysed) JFH biomass that had cracked, fibrous tissue with a relatively smooth surface. Fig. 14 shows that the acid hydrolysed JFH had some parallel cracks with an array of networks of particles that are highly packed. As could be seen on the acid hydrolysed JFH sample surface, the flocculent matter contains narrow pores spread across the structure and the pores are more obvious. The acid pretreatment effectively and efficiently 
removed or lessened hemicellulose, which might have altered the interaction between cellulose and lignin, as this may be responsible for the pores present. The alkali hydrolysed JFH showed that the cracked fibre tissue on the surface of the Page | 4147 raw and acid hydrolysed samples were ablated. The original surface was enhanced and the specific surface area was increased. The alkaline hydrolysed JFH contain a macroporous structure and new pores did not exist on its surface.

\section{Conclusion}

In this present study, Jatropha curcas L. fruit hull and seed shell, as well as their acid and alkali-pretreated biomasses were used as a novel raw material for the production of bio-oil via pyrolysis at $450{ }^{\circ} \mathrm{C}$ in a fix bed reactor. Both $\mathrm{H}_{2} \mathrm{SO}_{4}$ and $\mathrm{NaOH}$ could effectively degrade hemicellulose and break or weaken the linkages between lignin and hemicellulose. Furthermore, $\mathrm{NaOH}$ could effectively remove or lessen the lignin, whereas $\mathrm{H}_{2} \mathrm{SO}_{4}$ removed or lessened more hemicellulose. The removal or reduction of any lignin or hemicellulose is dependent on the concentration of acid or alkali used. GC-MS analyses of the raw and pretreated JSS and JFH revealed the presence of phenols, hydrocarbons and other essential chemical compounds like Furan (2 - Furancarboxaldehyde, 5-methyl-). The FT-IR results showed primary absorption bands that give fundamental knowledge of the type of chemical group present in the bio-oil of the raw and the pretreated pyrolysed JSS and JFH. The SEM photographs revealed the impact of pyrolysis on the raw and pretreated feedstocks. Meanwhile, the raw SEM micrograph showed a dense biomass structure, the pretreated biomass surface was damaged which therefore improved biomass porosity. Bio-oil thus obtained can be used as synthetic fuel after pretreatment (upgrading) or chemical feedstock after separation.

\section{Acknowledgement}

The authors are grateful to Tertiary Education Trust Fund (TETFund) Nigeria for their financial support.

\section{Competing Interest}

The authors declare no competing interests

\section{References}

Abdul Khalil, H.P.S., Sri Aprilla, N.A., Bhat, A.H., Jawaid, M., Paridah, M.T. and Rudi, D. (2013). A Jatropha Biomass as Renewable Materials for Biocomposites and its Applications. Renewable and Sustainable Energy Review, 33, 667-685.

Baruah, J., Nath, B.K., Sharma, R., Kumar, S., Deka, R.C., Baruah, D.C. and Kalita, E. (2018). Recent Trends in the Pretreatment of Lignocellulosic Biomass for ValueAdded Products. Frontiers in Energy Research, 6(14), 1-19.

Acar, S. and Ayanoglu, A. (2012). Determination of Higher Heating Values of biomass fuels. Energy Education Science and Technology Part A: Energy Science and Research, 28(2), 749-759.

Akintaro, A.O., Musa, A.I., Ajobo, J.A. and Oyewusi, T.F. (2017). The Potentials of Using Carbonized Corncob to Produced Briquettes as an Alternative to Fuelwood. FUTA Journal of Research in Sciences, 13(1), 137-145.

American Oil Chemists Society AOAC (1996). Official Methods and Recommended Practices of the American Oil Chemist Society, 3rd ed., Champaign IL:AOAC Press, USA.

Balat, M., Balat, H., Balat, M. and Kirtay, E. (2009). Main routes for the thermochemical of biomass into fuels and chemicals. Part 1: Pyrolysis systems. 
Energy Conversion and Management, 50, 3147-3157. doi: 10.1016/j.enconman. 2009.08.014.

Capunitan, J.A. and Capareda, S.C. (2013). Page | 4148 Characterization and separation of corn stover bio-oil by fractional distillation. Fuel, 112, 60-73. doi: 10.1016/j.fuel.20 13.04.079.

Carrier, M., Loppinet-Serani, A.. Denux, D., Lasnier, J-M., Ham-Pichavant, F., Cansell, F. and Aymonier, C. (2011). Thermogravimetric analysis as a new method to determine the lignocellulosic composition of biomass. Biomass and Bioenergy, 35, 298-307.

Chundawat, S.P.S., Beckham, G.T., Himmel, M.E. and Dale, B.E. (2011). Deconstruction of Lignocellulosic Biomass to Fuels and Chemicals. The Annual Review of Chemical and Biomolecular Engineering, 2(6), 1-25.

Crawshaw, J., Bras, W., Mant, G.R. and Cameron, R.E. (2002). Simultaneous SAXS and WAXS Investigations of Changes in Native Cellulose Fiber Microstructure on Swelling in Aqueous Sodium Hydroxide. Journal of Applied Polymer Science, 83, 1209-1218.

Den, W., Sharma, V.K., Lee, M., Nadadur, G. and Varma, R.S. (2018). Lignocellulosic Biomass Transformations via Greener Oxidative Pretreatment Processes: Access to Energy and Value-Added

Chemicals. Frontiers in Chemistry, 6(141), $1-23$.

Deng, Y., Zhao, Y., Wang, Y., Zhu, J.Y. and Ragauskas, A. (2008). Enhanced Enzymatic Hydrolysis of Spruce by Alkaline Pretreatment at low temperature. Biotechnology and Bioengineering, 99(6), 1320-1328.
Dhanavath, K.N., Islam, Md. S., Bankupalli, S., Bhargava, S.K., Shah, K. and Parthasarathy, R. (2017). Experimental investigation on the effect of pyrolytic Biooil during the liquefaction of Karanja Press Seed Cake. Journal of Environmental Chemical Engineering, 5, 4986-4993.

Elliot, D.C. (2007). Historical development in Hydroprocessing Bio-oils. Energy and Fuels, 21, 1792-1815.

Ertas, M. and Alma, M.H. (2010). Pyrolysis of laurel (Laurus nobilis L.) extraction residues in a fixed bed reactor: Characterization of bio-oil and bio-char. Journal of Analytical and Applied Pyrolysis, 88, 22-29.

Flores, R.A.C., Garcia, F.P., Sanchez, E.M.O., Miro, A.M.B. and Sandoval, O.A.A. (2017). Physico-Chemical Characterization of Agricultural Residues as Precursors for Activated Carbon Preparation. Preprints, $1,1-14$.

Gassan, J. and Bledzki, A. (1999). Alkali Treatment of Jute fibers: Relationship Between Structure and Mechanical Properties. Journal of Applied Polymer Science, 71, 623-629.

Galadima, A., Garba, Z.N., Ibrahim, B.M., Al Mustapha, M.N., Leke, L. and Adam, I.K. (2011). Biofuels Production in Nigeria: The Policy and Public Opinions. Journal of Sustainable Development, 4(4), 22-31.

Guilherme, A. de A., Fernandes, F.A.N., Dantas, P.V.F., Soares, J.C.J., dos Santos, E.S. and de Macedo, G.R. (2017). Pretreatments and Enzymatatic Hydrolysis of Sugarcane Bagasse Aiming at the Enhancement of the Yield of Glucose and Xylose. Brazillian Journal of Chemical Engineering, 34(4), 937-947. 
P.D. Grover, S.K. Mishra, Biomass Briquetting: Technology and Practices. Food and Agriculture organization of the United Nations, Regional Wood Energy Development programme in Asia GCP/RAS/154/NET Field Document N0.46, 1996 pp. 1-43.

Hendriks, A.T.W.M. and Zeeman, G. (2009). Pretreatments to enhance the digestibity of lignocellulosic biomass. Bioresource Technology, 100, 10-18.

Hosgun, E.Z. and Bozan, B. (2020). Effect of Different Types of Thermochemical Pretreatment on the Enzymatic Hydrolysis and the Composition of Hazelnut shells. Waste and Biomass Valorization, 11, 3739-3748. doi: 10.1007/s12649-01900711-z.

Ibitoye, A.A. (2017). Laboratory Manual on Basic Chemical Methods in Plant Analysis (1 ${ }^{\text {st }}$ ed., pp 1-131) FUTA Press, Akure, Nigeria.

Iliopoulou, E.F., Triantafyllidis, K.S. and Lappas, A.A. (2018). Overview of catalytic upgrading of biomass pyrolysis vapors toward the production of fuels and high-value chemicals. WIREs Energy and Environment, 8, 1-29.

Isaac, A., de Paula, J., Viana, C.M., Henriques, A.B., Malachias, A. and Montoro, L.A. (2018). From nano- to micrometer scale: the role of microwave-assisted acid and alkali pretreatments in the sugarcane biomass structure. Biotechnology for Biofuels, 11(73), 1-11.

Iroba, K.L., Tabil, L.G., Dumonceaux, T. and Baik O-D. (2013). Effect of alkaline pretreatment on chemical composition of lignocellulosic biomass using radio frequency heating. Biosystem Engineering, 116, 385-398.
Islam, A.K.M.A., Yaakob, Z. and Anuar, N. (2011). Jatropha: A Multipurpose Plant with Considerable Potential for the Tropics. Scientific Research and Essays, 6(13), 2597-2605.

Ji-Lu, Z. (2007). Bio-oil from fast pyrolysis of rice husk: Yields and related properties and improvement of the pyrolysis system. Journal of Analytical and Applied Pyrolysis, 80, 30-35.

Kratzeisen, M and Muller, J. (2009). Energy from the seed shells of Jatropha curcas. Landtechnik, 64 (6), 391-393.

Kumar, P., Barrett, D.M., Delwiche, M.J. and Stroeve, P. (2009). Methods for Pretreatment of Lignocellulosic Biomass for Efficient Hydrolysis and Biofuel Production. Industrial and Engineering Chemistry Research, 48, 3713-3729.

Lateef, F.A. (2010). Batch Production of Fatty Acid Propyl Esters (Biodiesel) from Oil Seed Crops. Unpublished M.Sc Thesis, Department of Pure and Industrial Chemistry, University of Nigeria. pp. 1-160.

Lateef, F.A., Daodu, S.O., Jere, P. and Yusuf, D. (2014c). Insecticidal Effect of Jatropha curcas L.Oil Phorbol Esters on the Nymph, Adult Cockroaches and Termites. International Journal of Applied Sciences and Engineering Research, 3(2), 495-503.

Lateef, F.A.,Jere, P. and Yusuf, D. (2014b). Harnessing Biofuel and Economic Potentials of Jatropha curcas for Sustainable Development in Nigeria: A Review. International Journal of Renewable Energy Technology Research, 3(1), 1-25.

Lateef, F.A., Onukwuli, O.D., Okoro, U.C., Ejikeme, P.M., and Jere, P. (2014a). Some 
Physical Properties and Oxidative Stability of Biodiesel Produced from Oil Seed Crops. Korean Journal of Chemical Engineering, 31(5), 725-731.

Page | 4150 Lateef, F.A., Okoro, U.C., Onukwuli, O.D. Alabere, H.Y. (2018). Some Chemical Properties of Fatty Acid Propyl Esters (Biodiesel) Produced via Transesterification of Oil seed Crops. FUTA Journal of Research in Sciences, 14(1), 40-53.

Lateef, F.A. and C. Asadu (2018). Effect of extraction methods on the storage and physico-chemical properties of Castor bean (Ricinus communis) and Physic nut (Jatropha curcas L.) oils. International Journal of Medical Science and advanced Bioscience, 3(4), 10-20.

Lateef, F.A. and Ogunsuyi, H.O. (2021). Jatropha curcas L. Biomass Transformation via Torrefaction: Surface Chemical Groups and Morphological Characterization. Current Research in Green and Sustainable Chemistry, 4(4), 110.

Lateef, F.A., Ogunsuyi, H.O., Adetuyi, A.O., Titiladunayo, I.F. (2021). Chemical compositions, surface chemistry and residual biomass surface morphology of Nigerian Jatropha curcas L. slowpyrolytic oil produced from de-oiled Jatropha curcas L. seed kernel. Dutse Journal of Pure and Applied Sciences, 7(2a), 189-210.

Lee, X. J., Lee, L.Y., Gan, S., ThangalazhyGopakumar, S. and Ng, H.K. (2017). Biochar potential evaluation of palm oil wastes through slow pyrolysis: Thermochemical characterization and pyrolytic kinetic studies. Bioresource Technology, 236, 155-163.
P. vd Linde, (2011). Regional Potential Assessment of Novel Bio-energy Crops in Fifteen ECOWAS countries. Being a short presentation on behalf of QUINVITA- a crop technology company applying stateof-the-art science and technology to create value in new sustainable industrial energy crops pp. 1-25.

Manurung, R., Wever, D.A.Z., Wildschut, J., Venderbosch, R.H., Hidayat, H., Van Dam, J.E.G., Leijenhorst, E.J., Broekhuis, A.A. and Heeres, H.J. (2009). Valorization of Jatropha curcas L. Plant Parts: Nut Shell Conversion to Fast Pyrolysis Oil. Food and Bioproducts Processing, 87, 187-196.

Menon, V. and Rao, M. (2012). Trends in bioconversion of lignocellulose: Biofuels, platform chemicals and biorefinery concept. Progress in Energy and Combustion Science, 38, 522-550.

Mohammed, T.H., Lakhmiri, R., Azmani, A. and Hassan, I.I. (2014). Bio-oil from Pyrolysis of Castor Shell. International Journal of Basic \& Applied Sciences IJBAS-IJENS, 14(6), 1-5.

Mohammed, I.Y., Abakr, Y., Kabir, F. and Yusuf, S. (2016). Effect of pretreatments of Napier grass with deionized water, sulfuric acid and sodium hydroxide on pyrolysis oil characteristics. Waste and Biomass valorization, 8(3), 735-733.

Murray, T., Resende, F. and Luo, G. (2014). Biooil: An Introduction to Fast Pyrolysis and its Applications. Washington state University extension fact sheet. FS104E.

Nahar, K. and Ozores-Hampton M. (2011). Jatropha: An Alternative Substitute to Fossil fuel. HS 1193 IFAS Extension University of Florida, Available at: 
http://edis.ifas.ufl.edu. $\quad$ (Accessed:17

February 2018).

Odetoye, T.E., Afolabi, T.J., Abu Bakar, M.S. and Titiloye, J.O. (2018). Thermochemical Page | $4151 \quad$ characterization of Nigerian Jatropha curcas fruit and seed residues for biofuel production. Energ. Ecol. Environ., 1(1), 18.

Ogunjobi, J.K. and Lajide, L. (2013). Characterisation of Bio-oil and Biochar from Slow-Pyrolysed Nigerian Yellow and White Corn Cobs. Journal of Sustainable Energy and Environment, 4, 77-84.

Openshaw, K. (2000). A Review of Jatropha curcas: An Oil Plant of unfulfilled Promise. Biomass and Bioenergy, 19, 1-15.

Oriez, V., Peydecastaing, J. and Pontalier, P-Y (2020). Lignocellulosic Biomass Mild Alkaline Fractionation and Resulting Extract Purification Processes: Conditions, Yields, and Purities. Clean Technology, 2, 91-115.

Parawira, W. (2010). Biodiesel Production from Jatropha curcas: A Review. Scientific Research and Essays, 5(14), 1796-1808.

Rambo, M.K.D., Alexandre, G.P., Rambo, M.C.D., Alves, A.R., Garcia, W.T. and Baruque, E. (2015). Characterization of biomasses from the north and northeast regions of Brazil for processes in biorefineries. Food Science and Technol, Campinas, 35(4), 605-611.

Sadaka, S.and Boateng, A.A. (2009). Pyrolysis and Bio-Oil. Agriculture and Natural Resources, Agriculture and Natural Resources, FSA 1052 university Arkansas Cooperative Extension Service Printing Services, Available at: http://www.uaex.edu. (Accessed: 14 February 2018).
Shah, S. Veses, R.C.and da Silva, R. (2016). A Comparative Study and Analysis of Two Types of Bio-Oil Obtained from Freshwater Algae and Microbial Treated Algae. Modern Chemistry \& Applications, 4(3), 1-7.

Shah, S. Veses, R.C. Inamullah and da Silva, R. (2016b). GC-MS and FTIR analysis of Bio-Oil Obtained from Freshwater Algae (spirogyra) collected from freshwater. International Journal of Environmental \& Agriculture Research (IJOEAR), 2(2), 134141.

Singh, R.N., Vyas, D.K., Srivastava, N.S.L. and Narra, M. (2008). SPRERI experience on holistic approach to utilize all parts of Jatropha curcas fruit for energy. Renewable Energy, 33, 1868-1873.

Subroto, E., Manurung, R. and Heeres, H.J. and Broekhuis, A.A. (2015). Optimization of mechanical oil extraction from Jatropha curcas L. kernel using response surface methods. Industrial Crops and Products, 63, 294-302.

Sutrisno, B. and Hidayat, A. (2017). Upgrading of Bio-oil from the pyrolysis of biomass over the rice husk ash catalyst. Second International Conference on Chemical Engineering (1CCE) UNPAR, 162, 1-7.

Sricharoenchaikul, V. and Atong, D. (2009). Thermal decomposition study on Jatropha curcas L. waste using TGA and fixed bed reactor. Journal of Analytical and applied Pyrolysis, 85, 155-162.

Tsegaye, B., Balomajumder, C. and Roy, P. (2010). Alkali delignification and Bacillus sp. BMPO1 hydrolysis of rice straw for enhancing biofuel yields. Bulletin of the National Research Centre, 43(136), 1-10. 
Tutt,M., Kikas, T. and Olt, J. (2012). Influence of different pretreatment methods on bioethanol production from Wheat straw. Agronomy Research Biosystem Engineering Special Issue, 1, 269-276.

Page | 4152

Wi, S.G., Cho, E.J., Lee, D-S.,Lee, S.J., Lee, Y.J. and Bae, H-J (2015). Lignocellulose conversion to biofuel: a new pretreatment greatly improves downstream biocatalytic hydrolysis of various lignocellulosic materials. Biotechnology for Biofuels, $8(28)$, 1-11. doi: 10.1186/s13068-015$0419-4$.

Wong, S., Wong, C.T., Onyiruka, S.O. and Akpanisi, L.E. (1998). University Organic Chemistry: The Fundamentals $\left(1^{\text {st }}\right.$ ed., pp 105-118) Manhattan Press (H.K.) Ltd in association with Africana-Fep Publishers Ltd., Nigeria.

Xu, F., Shi, Y-C., Wu, X., Theeraattananoon, K., Staggenborg, S. and Wang, D. (2011). Sulfuric acid pretreatment and enzymatic hydrolysis of photoperiod sensitive sorghum for ethanol production. Bioprocess Biosystem Engineering, 34, 485-492.

$\mathrm{Xu}, \mathrm{F}$., Shi, Y-C. and Wang, D. (2012). Structural features and changes of lignocellulose biomass during thermochemical pretreatments: A synchronton X-ray scattering study on photoperiod-sensitive sorghum. Carbohydrate Polymers, 88, 1149-1156.

Yang, D., Zheng, Y. and Zhang, R. (2009). Alkali Pretreatment of Rice Straw for Increasing Biodegradability. Paper presented at the 2009 ASABE Annual International Meeting, June 21-24, 2009 at Grand Sierra Resort and Casino Reno, Nevada. 